NASA Contractor Report 187142

AIAA-91-2198

\title{
Flow Visualization of a Rocket Injector Spray Using Gelled Propellant Simulants
}

James M. Green, Douglas C. Rapp, and James Roncace

Sverdrup Technology, Inc.

Lewis Research Center Group

Brook Park, Ohio

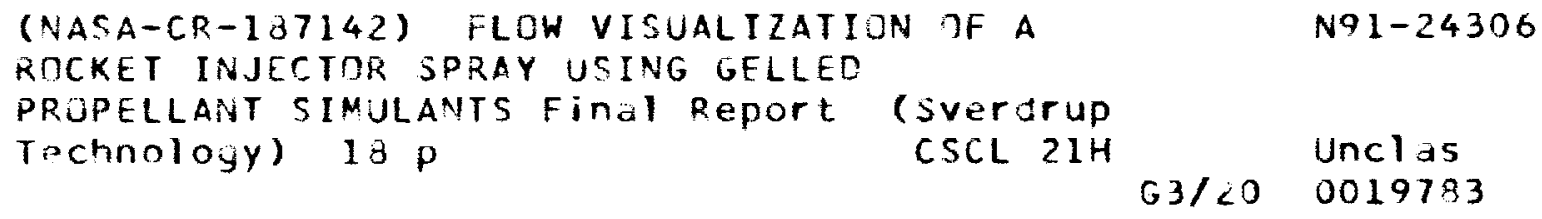

June 1991

Prepared for

Lewis Research Center

Under Contract NAS3-25266

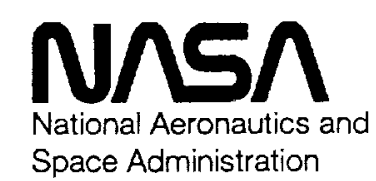





\title{
Flow Visualization of a Rocket Injector Spray
}

\author{
Using Gelled Propellant Simulants
}

\author{
James M. Green" \\ Douglas C. Rapp* \\ James Roncace \\ Sverdrup Technology, Inc. \\ NASA Lewis Research Center Group \\ Brook Park, Ohio 44142
}

\begin{abstract}
An experimental program was conducted at the NASA Lewis Research Center to compare the atomization characteristics of gelled and non-gelled propellant simulants. A gelled propellant simulant composed of water, sodium hydroxide, and an acrylic acid polymer resin as the gelling agent was used to simulate the viscosity of an aluminum/RP-1 metallized fuel gel. Water was used as a comparison fluid to isolate the rheological effects of the watergel and to simulate non-gelled RP-1. The water-gel was injected through the central orifice of a triplet injector element and the central post of a coaxial injector element. Nitrogen gas flowed through the outer orifices of the triplet injector element and through the annulus of the coaxial injector element and atomized the gelled and non-gelled liquids. Photographic images of the water-gel spray patterns at different operating conditions were compared with the images obtained using water and nitrogen. A laser light sheet, created by passing a five Watt argon-ion laser beam through a cylindrical lens, was used for illumination of the sprays. The results of the testing showed that the water sprays in general produced finer and more uniform atomization than the water-gel sprays. Rheological analysis of the water-gel showed that the relatively poor atomization of the water-gel was caused by the high viscosity of the water-gel delaying the transition to turbulence and inhibiting the atomization of the liquid water-gel.
\end{abstract}

\section{INTRODUCTION}

Future rocket missions will require increased payload mass to orbit, higher performance for orbit transfer, and high energy propellants for planetary missions. One concept which meets these mission goals is propulsion based on gelled, metallized propellants ${ }^{1-6}$. These propellants consist of a liquid fuel and solid metal particles mixed together in a stable suspension using a gelling agent. The high density and increased combustion energy of these propellants, as well as the added safety gelled propellants provide over conventional liquid and solid propellants, make them attractive for many applications. Before the theoretical advantages of gelled propellants can be realized, however, a number of critical technologies must be developed to obtain high combustion efficiency of the gelled propellants in rocket engines. One of the critical technologies identified is the injection performance of gelled and metallized gelled propellants ${ }^{7,8}$. In order to understand the fundamental characteristics of gelled propellant atomization, an experimental program is being conducted at the NASA Lewis Research Center to compare the atomization characteristics of gelled and non-gelled propellant simulants.

A gelled propellant simulant composed of water, sodium hydroxide, and an acrylic acid polymer resin as the gelling agent was used for this program. This gel formulation was chosen to simulate the rheological behavior of an aluminum/RP-1 metallized fuel gel. Water was employed as a constant-viscosity comparison fluid to simulate non-gelled RP-1. Both the water and water-gel accurately simulated the timeindependent rheological properties of the actual fuels. Although liquid oxygen (LOX) will be stored in the propellant tanks of an Al/RP-1 fueled engine, the LOX may be used as coolant and therefore may be gaseous by the time it reaches the main injectors. Therefore, a gaseous oxidizer simulant was chosen for this study. The water and water-gel were injected through the central orifice of a triplet injector element and the central post of a coaxial injector element.

"AIAA Member 
Nitrogen gas flowed through the outer orifices of the triplet injector element and through the annulus of the coaxial injector element and atomized the gelled and non-gelled liquids. The data taken in the study consisted of photographic images of the spray patterns at different operating conditions. The images of the water-gel/nitrogen sprays are compared with the images of the water/nitrogen sprays.

The use of cold flow testing and photographic imaging to study liquid atomization characteristics is a common approach for determining the qualitative and quantitative performance of an injector and the relative performance of the injector compared with different element designs or operating conditions. Cold flow injector spray studies have been performed in the past with metallized propellants ${ }^{7}$, but the present report presents the initial stages of an effort to fundamentally understand the atomization characteristics of gelled propellants and to determine the optimum injection concept for gelled, metallized fuels. This report presents a description of the facility, hardware, and photographic systems used in this study, as well as the rheological properties of the propellant simulants and a discussion of the photographic results of the atomization testing.

\section{APPARATUS}

\section{Test Facility}

The spray atomization tests were performed at Cell 21 of the Rocket Laboratory of NASA Lewis Research Center. This facility, which was designed for low thrust rocket engines and to investigate the performance of various unconventional propellants, contains the fluid flow systems required for steady, controllable flow rates of water, water-gel and gaseous nitrogen.

The water, water-gel, and gaseous nitrogen supply systems are shown in Figure 1. Water is supplied from a $310 \mathrm{kN} / \mathrm{m}^{2}$ (45 psig) domestic water line and passes through a manually operated pressure regulator (DW-1). The pressure regulator is used to vary the pressure downstream of the regulator to obtain the desired flow rates of water through the cavitating venturi (DW-3) and into the injector. Both the water and water-gel systems use cavitating venturi flow controllers to maintain constant liquid flow rates by setting known pressure drops across the cavitating venturi. A turbine flowmeter (DW-2) is used to measure the volume flow rate of water to insure that

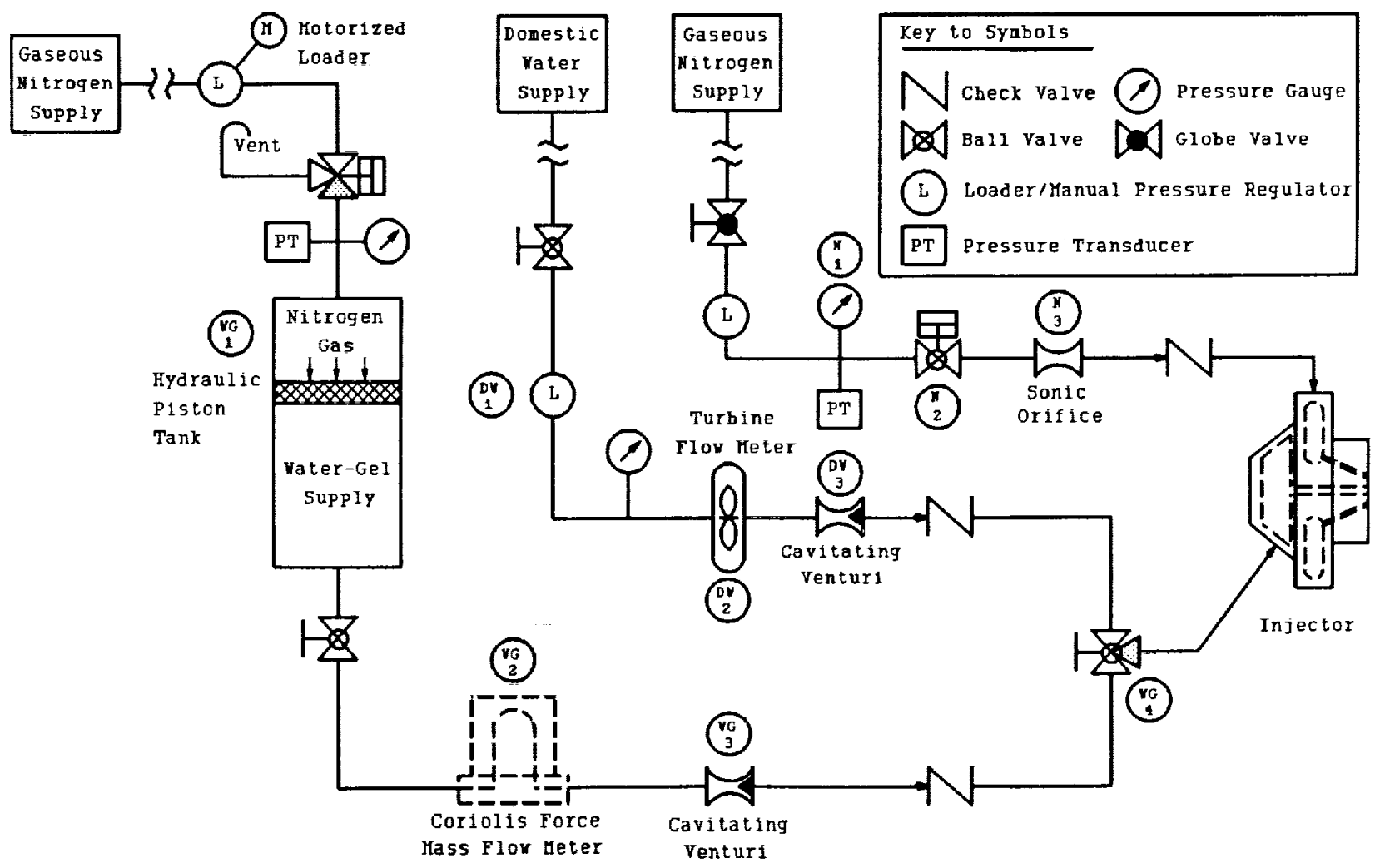

Figure 1: Schematic of the Fluid Flow System 
it remains constant throughout the test. The mass flow rate of water ranged from $4.54 \mathrm{~g} / \mathrm{sec}\left(0.010 \mathrm{lb}_{\mathrm{m}} / \mathrm{sec}\right)$ to $11.34 \mathrm{~g} / \mathrm{sec}$ $\left(0.025 \mathrm{lb}_{\mathrm{m}} / \mathrm{sec}\right)$. The water-gel is supplied from a hydraulic piston tank (WG-1) which uses a supply of gaseous nitrogen at varying pressure to feed the water-gel through the piping system. A Coriolis force mass flow meter (WG-2) is used to monitor the flow rate of gel through a cavitating venturi (WG-3) and into the injector. The Coriolis mass flow meter provides an accurate measure of liquid flow rate, with an expected uncertainty on the order of $1.7 \%^{8}$. The positive expulsion piston tank and the Coriolis force mass flow meter are used for the water-gel system because conventional fluid delivery and measurement techniques for constant viscosity fluids do not adapt well to variable viscosity fluids like the watergel. Water-gel mass flow rates were also varied from $4.54 \mathrm{~g} / \mathrm{sec}\left(0.010 \mathrm{lb}_{\mathrm{m}} / \mathrm{sec}\right)$ to $11.34 \mathrm{~g} / \mathrm{sec} \quad\left(0.025 \quad \mathrm{lb}_{\mathrm{m}} / \mathrm{sec}\right)$. The manually operated, three-way valve (WG4) provides the ability to select the fluid entering the injector and to change quickly between testing either with water or water-gel.

Gaseous nitrogen is supplied to the injectors at known flow rates by regulating the pressure of the gas upstream of a sonic orifice (N-3), according to a calibration curve. The pressure gauge $(\mathrm{N}-1)$ is used to measure the set-point pressure and the pneumatically operated valve $(\mathrm{N}-2)$ is used to start and stop the flow of nitrogen remotely. Gaseous nitrogen flow rates varied from $4.54 \mathrm{~g} / \mathrm{sec}(0.010 \mathrm{lb} / \mathrm{sec})$ to $9.07 \mathrm{~g} / \mathrm{sec}(0.020$ $\left.\mathrm{Ib}_{\mathrm{m}} / \mathrm{sec}\right)$.

\section{Test Hardware}

The test hardware consists of a triplet and a coaxial single element injector. These elements represent two of the most likely candidates for use with gelled, metallized propellants. In both cases, the liquid water or water-gel flow through the central orifice, while the nitrogen gas flows through the outer two orifices in the triplet and through the outer annulus in the coaxial element. A schematic of each of the injectors and the critical dimensions of each injector are given in Figures 2 and 3.

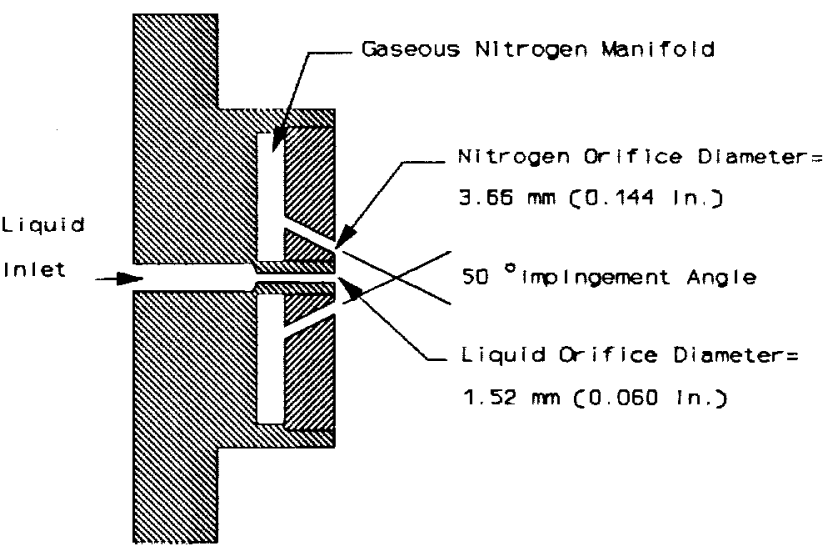

Figure 2: Schemat lc of Triplet Injector

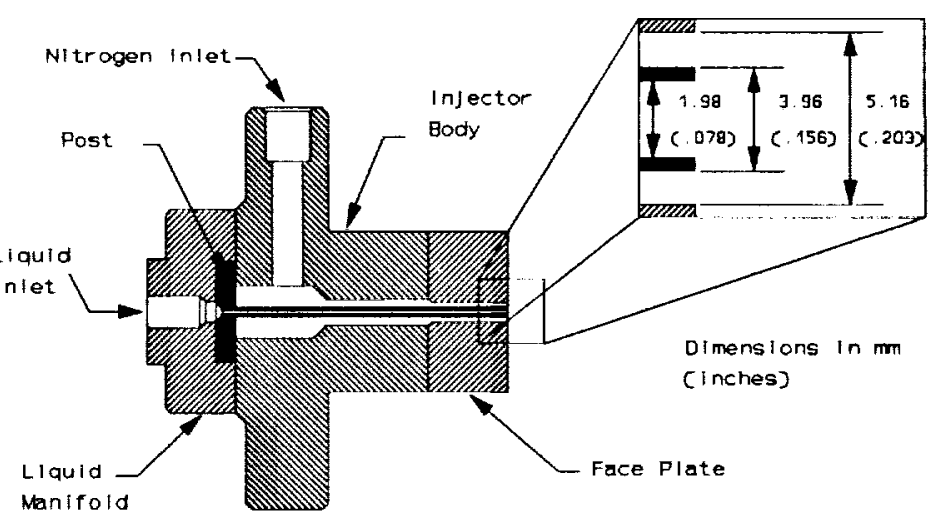

Figure 3: Schematic of Coaxial Injector

\section{Photographic Systems}

The images of the injector spray fields presented in this report were obtained using a $35 \mathrm{~mm}$ camera with an exposure time of one msec and an f-number of f/4.0. Film with a speed of 1600 was used for the prints. With an exposure time of one msec, a droplet moving with a speed of $500 \mathrm{in} / \mathrm{sec}$ would leave a 0.5 inch streak on the print, so single droplets could not be "frozen" in the frame. This exposure time was short enough, however, to provide qualitative information on the relative size and velocity of the droplets in the spray. The illumination used for the photographs is provided by a sheet of laser light formed by a continuous wave argon-ion laser operating at approximately five Watts total power. The laser beam passes through a cylindrical lens to form a sheet of light approximately $152 \mathrm{~mm}(6 \mathrm{in}$.) wide and $3 \mathrm{~mm}(0.1 \mathrm{in}$.) thick. The light sheet passes through the center of the injector spray perpendicular to the optical axis of the camera, 


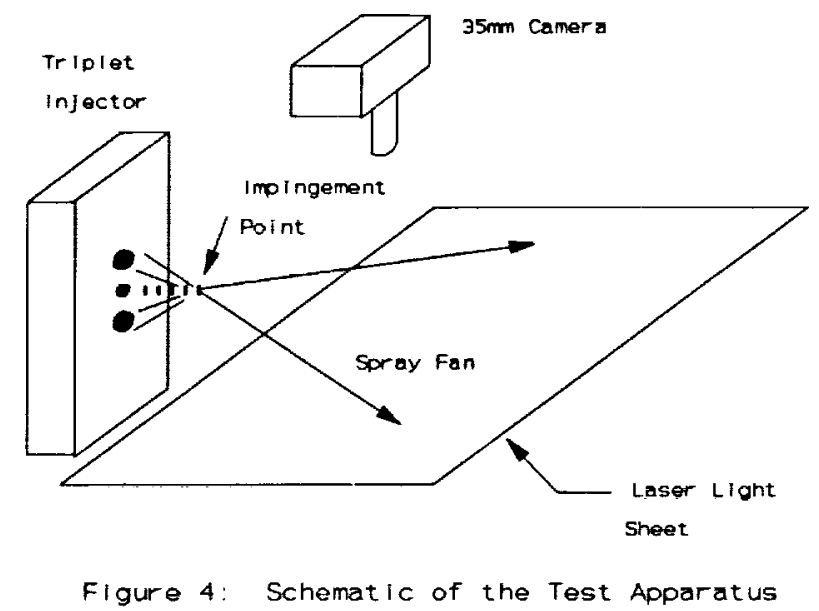

providing a sheet of illumination in the plane of the photographs, as shown in Figure 4. Conventional video tape of the spray was also taken for each operating condition.

\section{Test Procedure}

For each injector studied in this report, photographic images were obtained for twelve different flow

\begin{tabular}{|c|c|c|c|c|c|}
\hline \multicolumn{6}{|c|}{ TABLE 1. Injector Operating Conditions } \\
\hline \multicolumn{2}{|c|}{$\begin{array}{c}\text { Mass Flow Rate } \\
\text { g/sec } \\
\left(\mathrm{lb}_{\mathrm{m}} / \mathrm{sec}\right)\end{array}$} & \multirow[t]{2}{*}{$\begin{array}{c}\text { Mixture } \\
\text { Ratio } \\
\text { O/F }\end{array}$} & \multicolumn{2}{|c|}{$\begin{array}{c}\text { Mass Flow Rate } \\
\text { g/sec } \\
\left(\mathrm{lb}_{\mathrm{m}} / \mathrm{sec}\right)\end{array}$} & \multirow[t]{2}{*}{$\begin{array}{c}\text { Mixture } \\
\text { Ratio } \\
\text { O/F }\end{array}$} \\
\hline Liquid & Gas & & Liquid & Gas & \\
\hline $\begin{array}{c}4.54 \\
(0.010)\end{array}$ & $\begin{array}{c}4.54 \\
(0.010)\end{array}$ & 1.00 & $\begin{array}{c}7.57 \\
(0.017)\end{array}$ & $\begin{array}{c}6.80 \\
(0.015)\end{array}$ & 0.88 \\
\hline $\begin{array}{c}4.54 \\
(0.010)\end{array}$ & $\begin{array}{c}6.80 \\
(0.015)\end{array}$ & 1.50 & $\begin{array}{c}7.57 \\
(0.017)\end{array}$ & $\begin{array}{c}9.07 \\
(0.020)\end{array}$ & 1.18 \\
\hline $\begin{array}{c}4.54 \\
(0.010)\end{array}$ & $\begin{array}{c}9.07 \\
(0.020)\end{array}$ & 2.00 & $\begin{array}{c}9.07 \\
(0.020)\end{array}$ & $\begin{array}{c}4.54 \\
(0.010)\end{array}$ & 0.50 \\
\hline $\begin{array}{c}6.80 \\
(0.015)\end{array}$ & $\begin{array}{c}4.54 \\
(0.010)\end{array}$ & 0.67 & $\begin{array}{c}9.07 \\
(0.020)\end{array}$ & $\begin{array}{c}6.80 \\
(0.015)\end{array}$ & 0.75 \\
\hline $\begin{array}{c}6.80 \\
(0.015)\end{array}$ & $\begin{array}{c}6.80 \\
(0.015)\end{array}$ & 1.00 & $\begin{array}{c}9.07 \\
(0.020)\end{array}$ & $\begin{array}{c}9.07 \\
(0.020)\end{array}$ & 1.00 \\
\hline $\begin{array}{c}6.80 \\
(0.015)\end{array}$ & $\begin{array}{c}9.07 \\
(0.020)\end{array}$ & 1.33 & $\begin{array}{c}11.34 \\
(0.025)\end{array}$ & $\begin{array}{c}9.07 \\
(0.020)\end{array}$ & 0.80 \\
\hline
\end{tabular}

conditions for both water and nitrogen and water-gel and nitrogen sprays. The same operating conditions were used for each injector, and the liquid and gas mass flow rates and the mixture ratio are given in Table 1. The mixture ratio, $\mathrm{O} / \mathrm{F}$, is defined for this study as the nitrogen mass flow rate divided by the liquid mass flow rate. The $\mathrm{O} / \mathrm{F}$ values in this study were selected to represent a range of values around the optimum mixture ratio of the $\mathrm{Al} / \mathrm{RP}-1 / \mathrm{O}_{2}$ propellant system (optimum $\mathrm{O} / \mathrm{F}=1.1$ for $55 \%$ Al loading in RP-1). After the optical system and photographic parameters were adjusted to provide the highest quality images, two $35 \mathrm{~mm}$ photographs were taken for each flow condition.

\section{WATER-GEL FORMULATION AND RHEOLOGY}

Spray characteristics of a gas-liquid injector are generally a function of the liquid surface tension and the gas and liquid velocities, densities, and viscosities. ${ }^{9} \quad$ To qualitatively evaluate rheological effects on liquid spray characteristics, watergels were formulated with rheological behavior representing that of actual metallized propellants. This rheological behavior is non-Newtonian, i.e. the viscosity is variable and is dependent on the applied shear conditions. Non-Newtonian flow behavior is imparted on Newtonian water by introducing a swellable gellant, Carbopol 941, into the water. Carbopol resins are high-molecular-weight, watersoluble resins which out of solution physically appear as a fluffy, white powder. Chemically, these resins are acrylic acid polymers cross-linked with a polyalkenyl polyether. Additional material specifications and a scanning electron micrograph of the Carbopol 941 are provided in Table 2 (Bulk density refers to the density of the dry powder, including void spaces). ${ }^{10}$ 


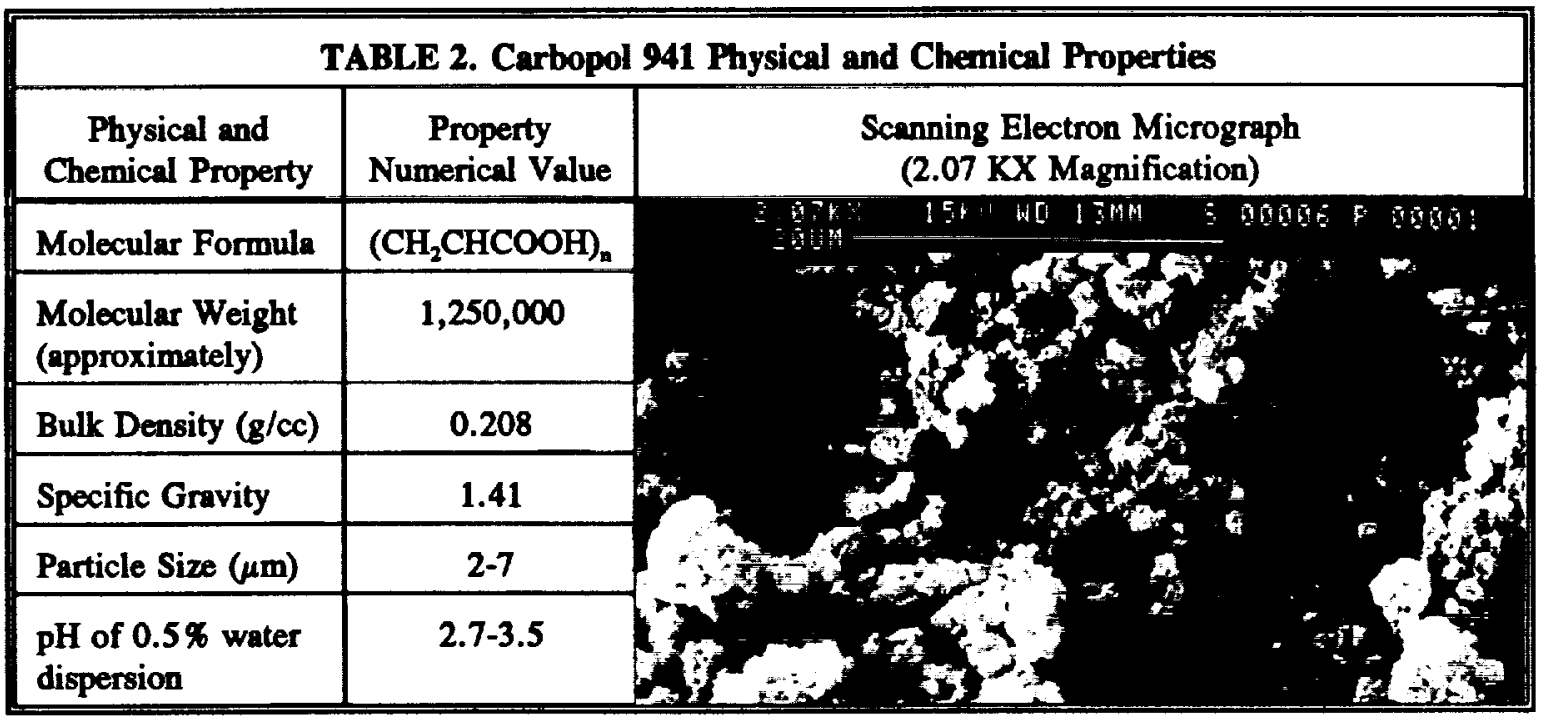

In formulating the water-gel, the gellant is introduced into the water using standard paddle-blade laboratory mixer. The resulting aqueous dispersion, or mucilage, has an acidic $\mathrm{pH}$ range of 2.8 to 3.2 , depending on resin concentration. Mucilage thickening is achieved by neutralizing the relaxed, highly coiled resin with inorganic basic solutions such as sodium hydroxide. Neutralization ionizes the Carbopol resin by generating negative charges along the backbone of the polymer and subsequently causing rapid uncoiling of the molecule into an extended structure (swellable gellant). Effective neutralization produces a final water-gel $\mathrm{pH}$ range of 6-7.

Small-scale formulation parametrics were conducted to isolate and evaluate the influence of formulation fluid component concentrations on water-gel rheological behavior. Flow characteristics similar to an aluminum/RP-1 (55 weight $\% \mathrm{Al}$ in RP1) metallized fuel gel were desired. The Al/RP-1 fuel possesses theoretical performance advantages as addressed in references 4-6. After performing these formulation parametrics, the water-gel composition used in the experimental spray evaluations was: 98.5 wt\% water, 1.0 wt\% sodium hydroxide solution (10\% concentration) and 0.5 wt \% Carbopol 941. This composition had a final water-gel $\mathrm{pH}$ of 6.

Beyond emulating metallized fuel rheology, simulation of other physical, chemical and thermal properties of the AI/RP-1 metallized fuel was not emphasized in the present study. A comparison of densities and equilibrium surface tension values are provided in Table 3. Since differences in the water and water-gel densities and the water and water-gel equilibrium surface tension values are small, utilization of water and water-gels isolates the theological effects on liquid spray characteristics.

Water-gels prepared with the desired rheology

\begin{tabular}{|c|c|c|c|}
\hline \multirow[t]{2}{*}{ Physical Property } & \multicolumn{3}{|c|}{ Fluid } \\
\hline & Water & Water-Gel & Al/RP-1 \\
\hline Density, $\rho(g / c c)$ & $0.997^{*}$ & $0.999^{-}$ & $1.357^{-\prime}$ \\
\hline $\begin{array}{l}\text { Equilibrium Surface } \\
\text { Tension, } \sigma(\mathrm{N} / \mathrm{m})\end{array}$ & 0.0712 & 0.0763 & $\begin{array}{c}\begin{array}{c}\text { Not } \\
\text { available }\end{array} \\
\end{array}$ \\
\hline Yield Point, $\tau_{y}(\mathrm{~Pa})$ & $\ldots$. & 21.9 & $25.9^{\prime}$ \\
\hline
\end{tabular}


simulation are pseudoplastic fluids which exhibit a yield point. Yield points impart a low-shear solid consistency to the material, since no flow is initiated below the yield stress. As indicated in Table 3, Newtonian fluids such as water do not exhibit a yield point. However, gelled materials typically form a yield point through the interactions of gellant particulates within the fluid. The water-gel and Al/RP-1 metallized fuel gel have comparable yield points. These yield points are greatly exceeded in injector fluid flow, hence their influence is negligible here. power law rheological model $\left(\tau=\mathrm{K}^{*}(\dot{\gamma})^{n}\right)$ was mathematically fitted to the experimental data region to facilitate data extrapolation. Power laws mathematically model the behavior of pseudoplastic fluids without yield points. Since the gels evaluated in this study have such small yield points, the model is fairly accurate as demonstrated by the correlation coefficient, $R^{2}$. An $R^{2}$ correlation coefficient of 1 represents precise model agreement with the experimental data. It must be stressed that all apparent viscosities extrapolated outside the measurement arena are strictly for qualitative use.

Pseudoplastic implies a shear thinning effect in which viscosity diminishes with increasing applied shear. Since viscosity is a function of variables other than temperature, the rheology is non-Newtonian and viscometric values are reported as "apparent" viscosities at specific shear rates. Newtonian fluids such as water have a constant "absolute" viscosity at any isothermal flow condition. The rheological behavior of the water and Al/RP-1 fuel gels was measured under the same temperature and shear conditions in a cup-and-bob rotational viscometer.

Temporal rheological effects ${ }^{13}$, such as thixotropy and gel relaxation time, are not specifically addressed in this present investigation. Thixotropy is a shear- thinning, viscosity-reducing effect with time. Hence, the duration of applied shear through the delivery system and injector flow passages affects the fluid viscosity. Due to viscometer limitations, the magnitude of this viscosity reduction was not assessed for the water-gels but it is believed to improve atomization. After the fluid is ejected from the injector, the applied shear on the fluid rapidly diminishes and the gel structure begins to reform. The time duration to reconstruct an equilibrium (zero shear) gel structure is the gel relaxation time. Small gel relaxation times may reduce droplet formation times and, in turn, improve spray atomization. In the future, timedependent behavior will be quantified.

Table 4 summarizes the isothermal rheological behaviors of water, RP-1, water-gel, and Al/RP-1 metallized fuel gel. Rheological data points beyond an applied shear rate of $300 \mathrm{~s}^{-1}$ are not within the experimental capacity of present NASA Lewis equipment. Hence, a

\begin{tabular}{|c|c|c|c|c|}
\hline \multirow{2}{*}{$\begin{array}{c}\text { Applied } \\
\text { Shear } \\
\text { Rate } \\
\left(\mathbf{s}^{-1}\right)\end{array}$} & \multicolumn{2}{|c|}{$\begin{array}{l}\text { Absolute } \\
\text { Viscosity } \\
(\mathrm{mPa} \cdot \mathrm{s})\end{array}$} & \multicolumn{2}{|c|}{$\begin{array}{l}\text { Power Law Apparent } \\
\text { Viscosity (mPa•s) }\end{array}$} \\
\hline & Water ${ }^{*}$ & RP-1 - & Water-Gel" & $\mathrm{Al} / \mathrm{RP}-1^{* \prime \prime}$ \\
\hline 1 & 0.89 & 1.89 & 16750 & 13480 \\
\hline 5 & 0.89 & 1.89 & 6435 & 5770 \\
\hline 10 & 0.89 & 1.89 & 4262 & 4004 \\
\hline 50 & 0.89 & 1.89 & 1637 & 1714 \\
\hline 100 & 0.89 & 1.89 & 1084 & 1189 \\
\hline 500 & 0.89 & 1.89 & 417 & 509 \\
\hline 1,000 & 0.89 & 1.89 & 276 & 353 \\
\hline 5,000 & 0.89 & 1.89 & 106 & 151 \\
\hline 10,000 & 0.89 & 1.89 & 70 & 105 \\
\hline 50,000 & 0.89 & 1.89 & 27 & 45 \\
\hline 100,000 & 0.89 & 1.89 & 18 & 31 \\
\hline
\end{tabular}

Shadal numbers are power law model predictions outside of the experimental data region in which the model was constructed.

* Reference 11

** Experimentally Measured

\# Power Law Model, $\tau=16.75 *(\dot{\gamma})^{0.4056}, \mathrm{R}^{2}=0.99163$,

\#\# Reference 12

$$
\mu_{\mathrm{a}}=16,750 *(\dot{\gamma})^{-0.5944}
$$

Power Law Model, $\tau=13.48^{*}(\dot{\gamma})^{0.4728}, \mathrm{R}^{2}=0.99429$,

$$
\mu_{\mathrm{a}}=13,480^{*}(\dot{\gamma})^{-0.5272}
$$


testing demonstrated similar lowshear-rate $\quad\left(0-300 \mathrm{~s}^{-1}\right)$ flow behavior as compared with the Al/RP-1 metallized fuel gel. Although no quantitative observations may be made concerning the higher shear rate data, qualitatively speaking, the water-gel provided an accurate simulation of the viscosity properties of the aluminum/RP-1 fuel. The viscosity of RP-1 was determined to be $1.89 \mathrm{mPa} \cdot \mathrm{s}$, so the water accurately simulated the viscosity of RP-1.

By modifying the qualitative water-gel power law model, insight is gained with respect to the actual experimental flow conditions within the injector. Model modification is necessary to account for differences in flow geometries, since Couette flow occurs in the rotational viscometer and pipe flow occurs in the injector. This modification also requires a redefinition of terminology, with applied shear rate being changed to effective shear rate, and apparent viscosity to effective viscosity. Reynolds number is defined in the traditional manner, $\operatorname{Re}=d v \rho /(v i s c o s i t y)$, where viscosity is absolute viscosity for the Newtonian Reynolds number and effective viscosity for the generalized Non-Newtonian Reynolds number.

Tables 5 and 6 describe the water and water-gel flow conditions across the smallestdiameter fuel injector passage. In this study, this passage is the triplet fuel injector exit passage, which is $1.52 \mathrm{~mm}(0.06 \mathrm{in}$.) in diameter. Small differences in fluid flow velocities between water and the water-gel are due to fluid density differences. In tum, the effective shear rates at each mass flow condition are slightly different for the
TABLE 5. Experimental Flow Conditions of Water at $25^{\circ} \mathrm{C}$

\begin{tabular}{||c|c|c|c|c||}
\hline $\begin{array}{c}\text { Mass Flow } \\
\text { Rate, } \\
\mathrm{g} / \mathrm{s} \\
\left(\mathrm{b}_{\mathrm{m}} / \mathrm{s}\right)\end{array}$ & $\begin{array}{c}\text { Water Flow } \\
\text { Velocity, } \\
\mathrm{cm} / \mathrm{s} \\
(\mathrm{in} / \mathrm{s})\end{array}$ & $\begin{array}{c}\text { Effective } \\
\text { Shear } \\
\text { Rate } \\
\left(\mathrm{s}^{-1}\right)\end{array}$ & $\begin{array}{c}\text { Absolute } \\
\text { Viscosity } \\
(\mathrm{mPa} \cdot \mathrm{s})\end{array}$ & $\begin{array}{c}\text { Newtonian } \\
\text { Reynolds } \\
\text { Number }\end{array}$ \\
\hline $\begin{array}{c}4.54 \\
(0.010)\end{array}$ & $\begin{array}{c}249.4 \\
(98.2)\end{array}$ & 13,094 & 0.8904 & 4,257 \\
\hline $\begin{array}{c}6.80 \\
(0.015)\end{array}$ & $\begin{array}{c}374.1 \\
(147.3)\end{array}$ & 19,641 & 0.8904 & 6,385 \\
\hline $\begin{array}{c}7.57 \\
(0.017)\end{array}$ & $\begin{array}{c}416.6 \\
(164.0)\end{array}$ & 21,868 & 0.8904 & 7,109 \\
\hline $\begin{array}{c}9.07 \\
(0.020)\end{array}$ & $\begin{array}{c}498.9 \\
(196.4)\end{array}$ & 26,189 & 0.8904 & 8,513 \\
\hline $\begin{array}{c}11.34 \\
(0.025)\end{array}$ & $\begin{array}{c}623.6 \\
(245.5)\end{array}$ & 32,736 & 0.8904 & 10,642 \\
\hline
\end{tabular}

\begin{tabular}{|c|c|c|c|c|}
\hline $\begin{array}{l}\text { Mass Flow } \\
\text { Rate, } \\
\text { g/s } \\
\left(\mathrm{lb}_{\mathrm{m}} / \mathrm{s}\right)\end{array}$ & $\begin{array}{c}\text { Gel Flow } \\
\text { Velocity, } \\
\mathrm{cm} / \mathrm{s} \\
\text { (in/s) }\end{array}$ & $\begin{array}{c}\text { Effective } \\
\text { Shear } \\
\text { Rate } \\
\left(s^{-1}\right)\end{array}$ & $\begin{array}{l}\text { Effective } \\
\text { Viscosity } \\
\text { (mPa.s)" }\end{array}$ & $\begin{array}{c}\text { Generalized } \\
\text { Non-Newtonian } \\
\text { Reynolds } \\
\text { Number }\end{array}$ \\
\hline $\begin{array}{c}4.54 \\
(0.010)\end{array}$ & $\begin{array}{l}248.9 \\
(98.0)\end{array}$ & 13,068 & 68 & 56 \\
\hline $\begin{array}{c}6.80 \\
(0.015)\end{array}$ & $\begin{array}{c}373.4 \\
(147.0)\end{array}$ & 19,602 & $\$$ & 107 \\
\hline $\begin{array}{c}7.57 \\
(0.017)\end{array}$ & $\begin{array}{c}415.8 \\
(163.7)\end{array}$ & 21,824 & 50 & 126 \\
\hline $\begin{array}{c}9.07 \\
(0.020)\end{array}$ & $\begin{array}{c}497.8 \\
(196.0)\end{array}$ & 26,136 & 45 & 168 \\
\hline $\begin{array}{c}11.34 \\
(0.025)\end{array}$ & $\begin{array}{c}622.3 \\
(245.0)\end{array}$ & 32,670 & 39 & 240 \\
\hline
\end{tabular}

Shaded numbers are power law model predictions outside of the experimental data region in which the model was constructed.

* Power Law Model, $\tau_{w}=19.01 *\left(\dot{\gamma}_{e}\right)^{0.4056}, \mu_{c}=19,010^{*}\left(\dot{\gamma}_{c}\right)^{0.5944}$ 
Again, the non-Newtonian viscosity and generalized Reynolds number data reported in Table 6 are not quantitatively valid. A definite conclusion can be drawn from the tables, however, because the numerical values qualitatively describe the correct flow situation. In comparison to water, the water-gel has significantly larger viscosity values and smaller Reynolds numbers at comparable flow velocities. Hence, due to their higher viscosity, gels retard the onset of turbulence, which occurs for $\operatorname{Re}>2100$. Visual observations from this study qualitatively confirm the laminar flow behavior of the water-gels and subsequent poor atomization.

\section{RESULTS AND DISCUSSION}

The photographic images obtained in this study provide a qualitative analysis of the atomization characteristics of the water and water-gel sprays, which simulate RP-1 and gelled Al/RP-1 propellants. Conventional video tape of the sprays was also studied to assist in determining the relative "atomization quality" of the sprays. The effects of rheology on the spray characteristics were evaluated by maintaining relatively constant liquid surface tension, density, and flow velocity conditions between the water and water-gel. Comparisons between water and water-gel can be made for similar operating conditions, and trends can be identified. Since the water and water-gel accurately simulate the rheological behavior of the RP-1 and Al/RP-1 respectively, the trends in the photographic data are expected to be similar to those found with the actual RP-1 and Al/RP-1 propellants. The qualitative results for both the triplet and coaxial injector elements are given in this section.

\section{Triplet Injector Results}

In general, the triplet injector element produced a fan of spray contained mainly in the image plane. The relative quality of the atomization can be determined by studying the uniformity of the spray fan and the apparent sizes of the droplets in the spray (note that the actual droplet sizes cannot be measured due to the distortion caused by the finite exposure time of the photographs). Qualitatively, the best operating conditions tested produce a uniform spray of small droplets, while the poorly atomized conditions produce uneven fans with large droplets.

For each of the twelve operating conditions used in this study, the water/nitrogen sprays produced a more uniform spray of smaller droplets than the watergel/nitrogen sprays under identical conditions. The higher viscosity of the water-gel increases the difficulty of breaking up the water-gel into extremely small droplets, whereas the non-gelled water readily atomizes into a fine mist at the optimum operating conditions. While the data show that the water-gel does not atomize as well as the water, quantitative data are required to determine if a gelled liquid spray is capable of sufficient atomization to provide highly efficient combustion.

To illustrate the difference between the water and water-gel atomization, Figures 5 and 6 show the three highest quality and the three lowest quality conditions, respectively, for both water and water-gel sprays. These figures show the general trend that the best atomization occurs at operating conditions with the highest liquid mass flow rates, while the worst performance is obtained at the conditions of lowest liquid mass flow rate. These conditions correspond with higher Reynolds number for the optimum operating conditions and lower Reynolds number for the poorly atomizing operating conditions. Thus, for low liquid mass flow rate the Reynolds number is low, viscous forces dominate over inertial forces, and poor atomization results. The similarity in the trends for both the water and water-gel indicate that the same factors influence overall atomization for both fluids and that the relative performance is determined by the hardware design under constant operating conditions.

Another general trend can be identified by referring to Figure 7, which shows the effect of total mass flow rate on the atomization of water and water-gel for constant mixture ratios of 1.0. This figure reinforces the conclusion that atomization improves as the mass flow rate increases.

To provide further evidence of the importance of liquid mass flow rate, Figures 8 and 9 present the images of water and water-gel atomization at different liquid mass flow rates for constant nitrogen mass flow rate equal to $9.07 \mathrm{~g} / \mathrm{sec}\left(0.020 \mathrm{Ib}_{\mathrm{m}} / \mathrm{sec}\right)$. Both of these figures show that as the liquid mass flow rate increased, the atomization improved. Similar results are obtained if the images with constant nitrogen flow rates of 6.80 and $4.54 \mathrm{~g} / \mathrm{sec}(0.015$ and 0.010 $\mathbf{l b}_{\mathrm{m}} / \mathrm{sec}$ ) are studied. This trend is expected since the larger liquid mass flow rates correspond to higher Reynolds numbers and therefore more efficient atomization. No distinct trend in the data was observed when gas mass flow rate was varied at 


\section{ORIGINAL PAGE \\ BLACK AND WHITE PHOTOGRAPH}

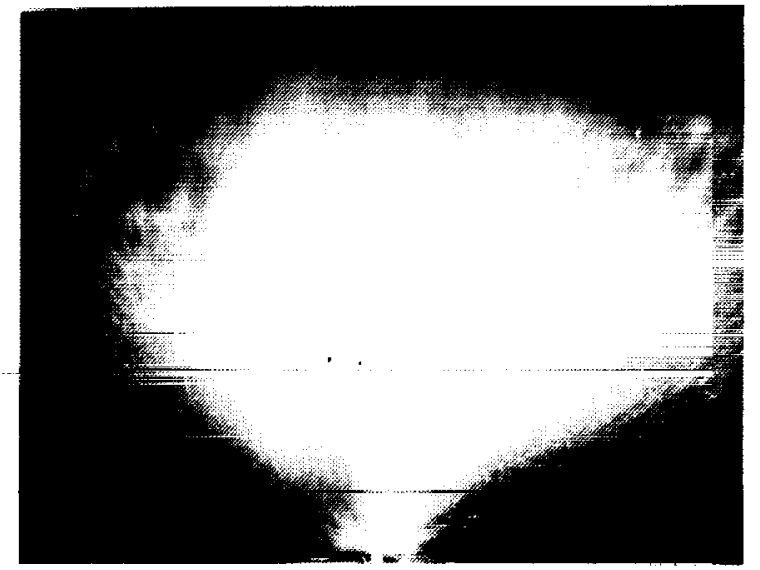

a) $\dot{m}_{\mathrm{N} 2}=9.07 \mathrm{~g} / \mathrm{s}(0.020 \mathrm{lb} / \mathrm{s}) ; \dot{m}_{4 p O}=11.34 \mathrm{~g} / \mathrm{s}(0.025 \mathrm{lb} / \mathrm{s}) ; 0 / \mathrm{F}=0.80$

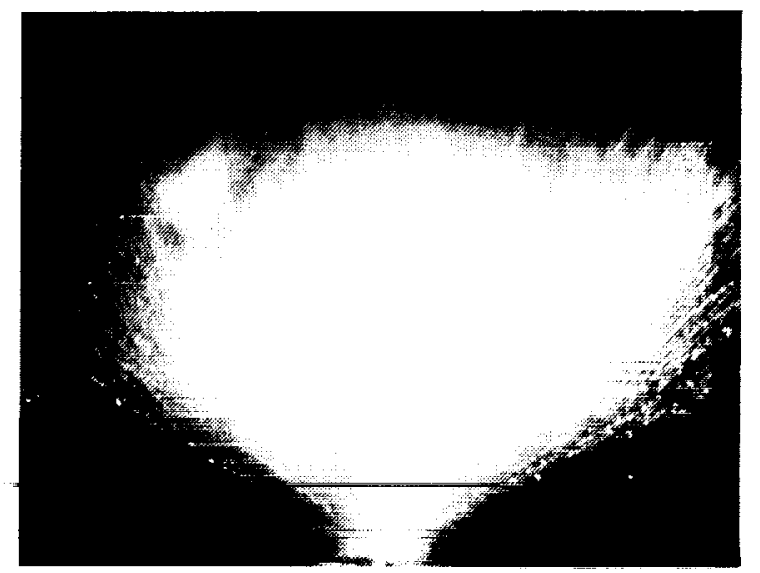

c) $\dot{m}_{* 2}=6.80 \mathrm{~g} / \mathrm{s}(0.015 \mathrm{lb} / \mathrm{s}) ; \mathrm{h}_{\mathrm{q}}=9.07 \mathrm{~g} / \mathrm{s}(0.020 \mathrm{lb} / \mathrm{s}) ; 0 / F=0.75$

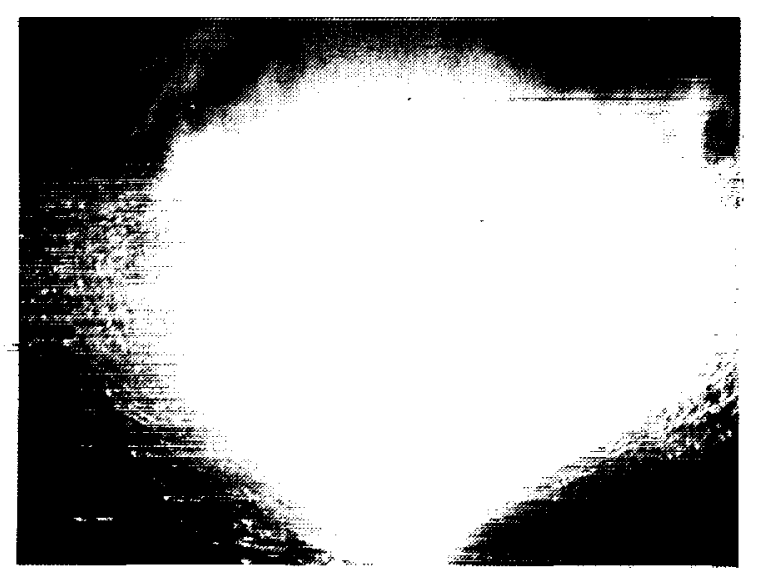

e) $\dot{m}_{w_{2}}=9.07 \mathrm{~g} / \mathrm{s}(0.020 \mathrm{lb} / \mathrm{s}) ; \mathrm{r}_{\mathrm{z}}=9.07 \mathrm{~g} / \mathrm{a}(0.020 \mathrm{lb} / \mathrm{g}) ; 0 / \mathrm{F}=1.00$

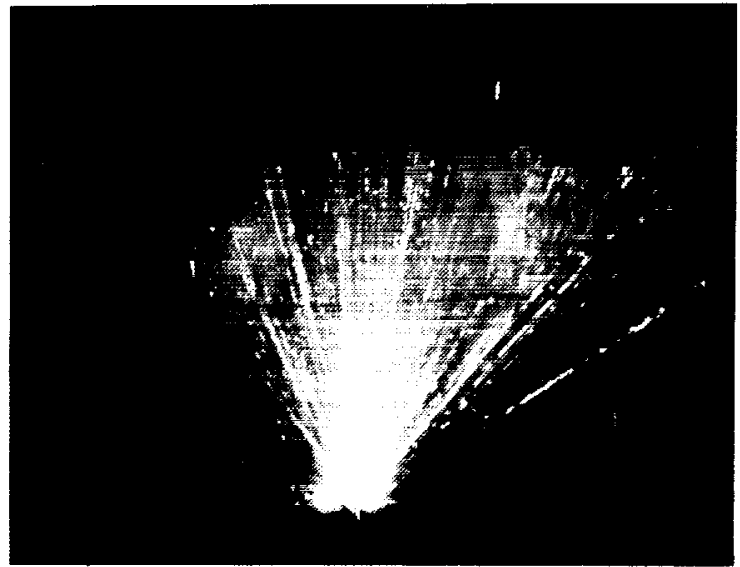

b) $\mathrm{m}_{\mathrm{N} 2}=9.07 \mathrm{~g} / \mathrm{s}(0.020 \mathrm{lb} / \mathrm{s}) ; \mathrm{m}_{\mathrm{zd}}=11.34 \mathrm{~g} / \mathrm{s}(0.025 \mathrm{lb} / \mathrm{m}) ; 0 / \mathrm{F}=0.80$

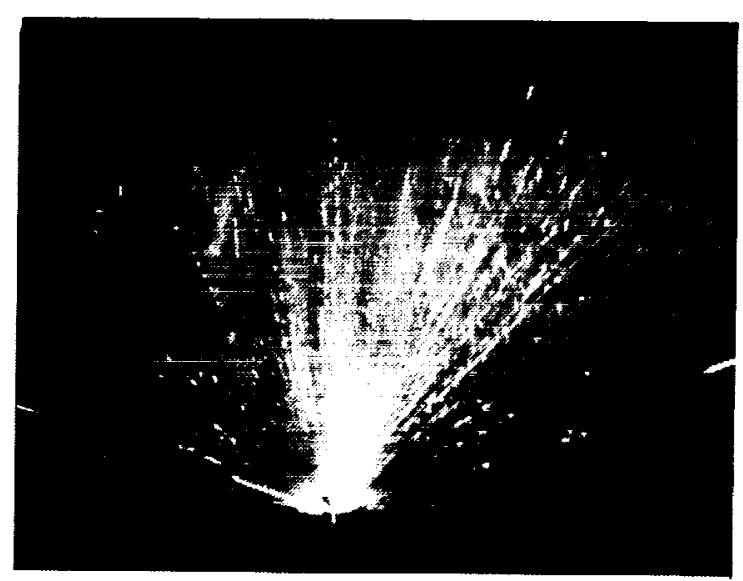

d) $h_{W / 2}=9.07 \mathrm{~g} / \mathrm{s}(0.020 \mathrm{lb} / \mathrm{s}) ; \mathrm{m}_{\mathrm{zd}}=9.07 \mathrm{~g} / \mathrm{s}(0.020 \mathrm{lb} / \mathrm{m}) ; 0 / F=1.00$

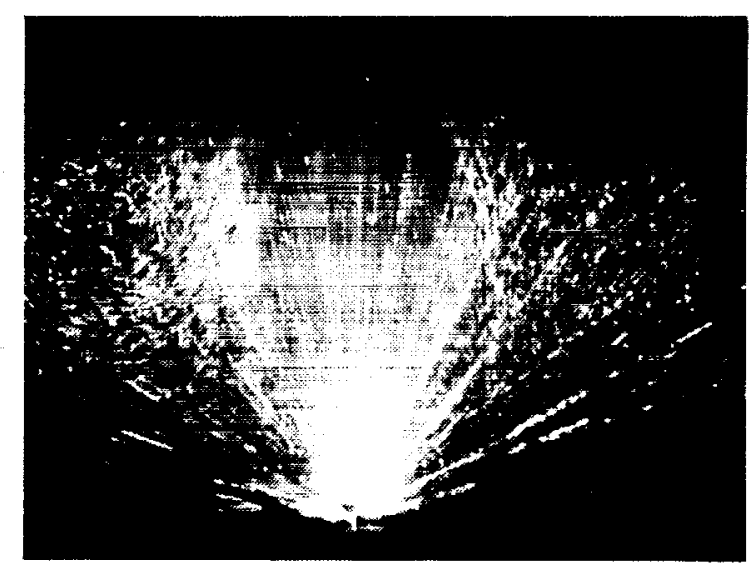

f) $\mathrm{t}_{\mathrm{T}_{2}}=6.80 \mathrm{~g} / \mathrm{s}(0.015 \mathrm{lb} / \mathrm{s}) ; \dot{m}_{z+1}=9.07 \mathrm{~g} / \mathrm{s}(0.020 \mathrm{lb} / \mathrm{s}) ; 0 / F=0.80$

Figure 5: Optimum operating conditions for water and water-gel for the triplet injector. 


\section{ORIGINAL PAGE \\ BLACK AND WHITE PHOTOGRAPH}

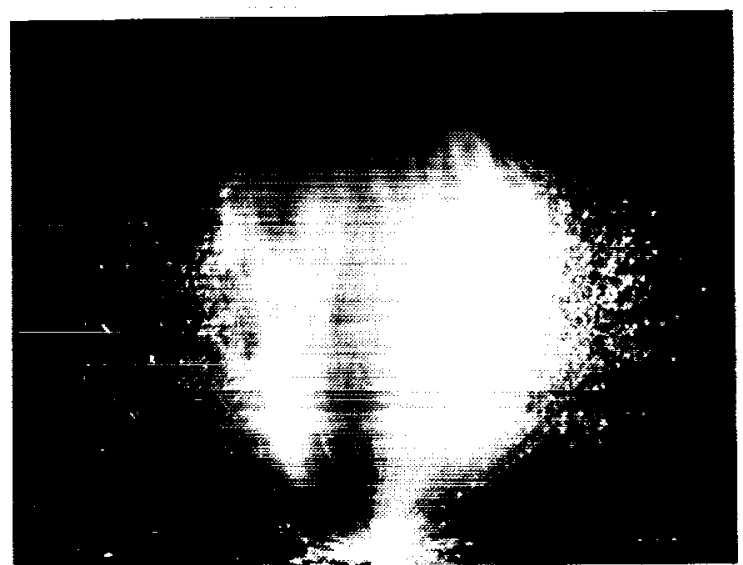

a) $\dot{\mathrm{m}}_{\mathrm{w} 2}=6.80 \mathrm{~g} / \mathrm{s}(0.015 \mathrm{lb} / \mathrm{g}) ; \dot{\mathrm{m}}_{\mathrm{q} 20}=4.54 \mathrm{~g} / \mathrm{s}(0.010 \mathrm{lb} / \mathrm{s}) ; 0 / \mathrm{F}=1.50$

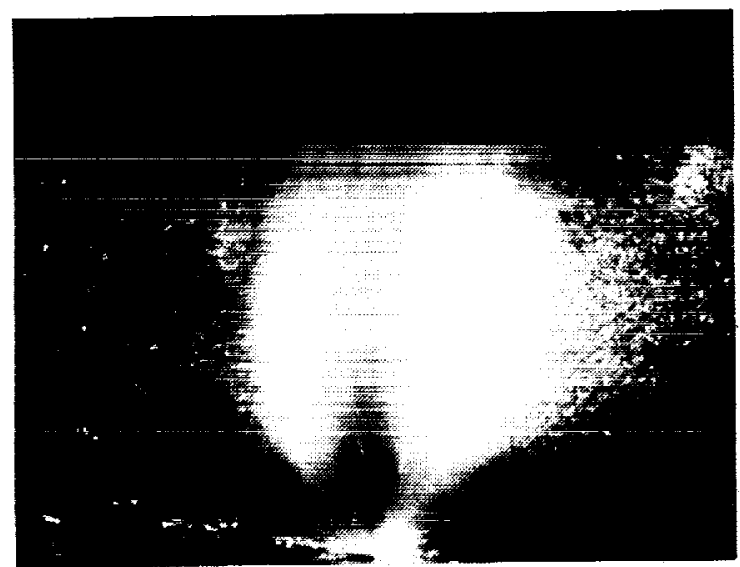

c) $\dot{\mathrm{m}}_{\mathrm{k} 2}=9.07 \mathrm{~g} / \mathrm{s}(0.020 \mathrm{lb} / \mathrm{s}) ; \dot{\mathrm{m}}_{\mathrm{H} 20}=4.54 \mathrm{~g} / \mathrm{s}(0.010 \mathrm{lb} / \mathrm{s}) ; 0 / \mathrm{F}=2.00$

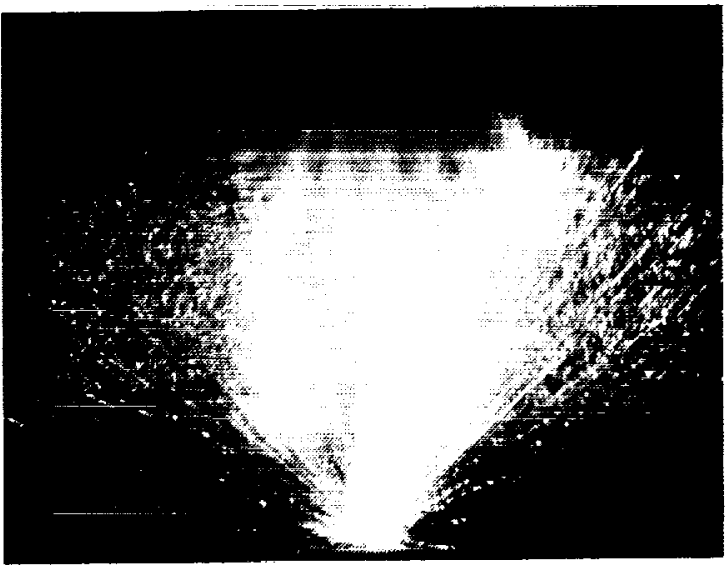

e) $\mathrm{m}_{\mathrm{W} 2}=4.54 \mathrm{~g} / \mathrm{s}(0.010 \mathrm{lb} / \mathrm{s}) ; \mathrm{m}_{\mathrm{HzO}}=4.54 \mathrm{~g} / \mathrm{s}(0.010 \mathrm{lb} / \mathrm{g}) ; 0 / \mathrm{F}=1.00$

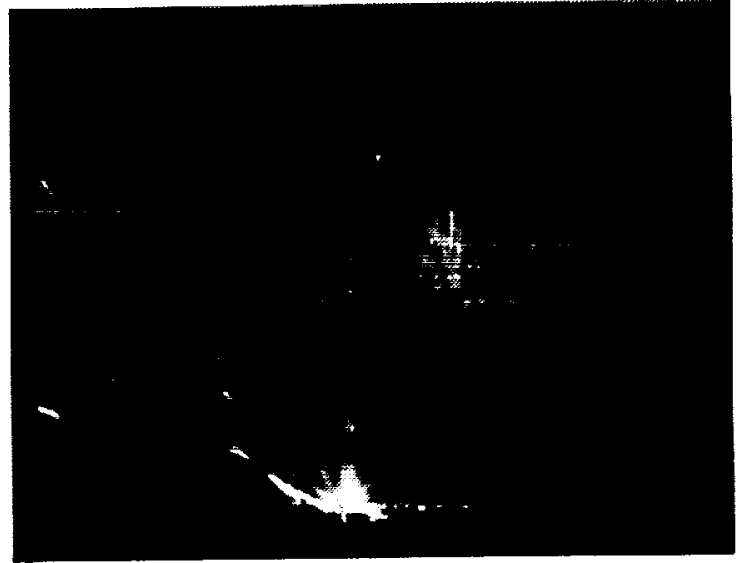

b) $\mathrm{m}_{\mathrm{w} z}=9.07 \mathrm{~g} / \mathrm{a}(0.020 \mathrm{lb} / \mathrm{s}) ; \mathrm{m}_{\mathrm{zd}}=4.54 \mathrm{~g} / \mathrm{s}(0.010 \mathrm{lb} / \mathrm{s}) ; 0 / \mathrm{F}=2.00$

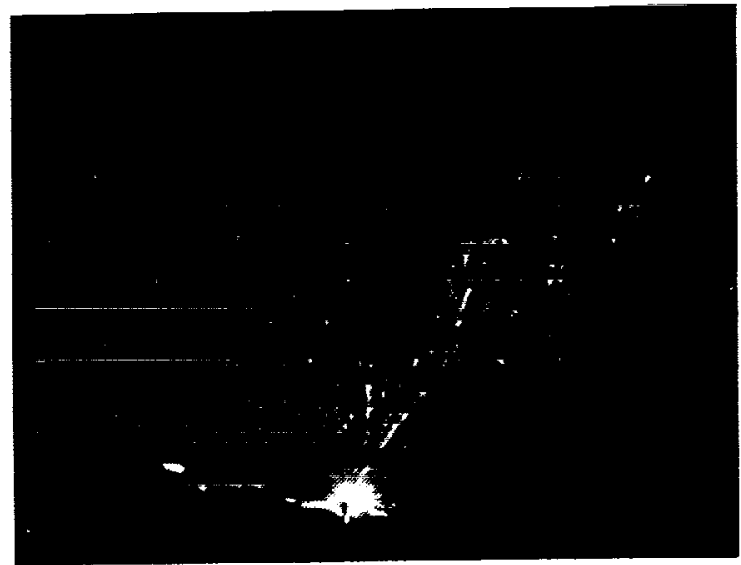

d) $\mathrm{m}_{\mathrm{W} / 2}=6.80 \mathrm{~g} / \mathrm{s}(0.015 \mathrm{lb} / \mathrm{s}) ; \mathrm{m}_{\mathrm{zd}}=4.54 \mathrm{~g} / \mathrm{s}(0.010 \mathrm{lb} / \mathrm{s}) ; 0 / \mathrm{F}=1.50$

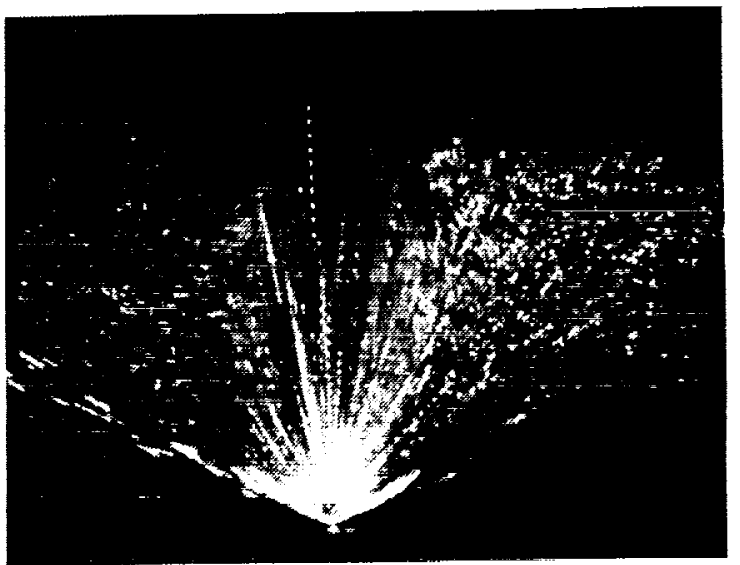

f) $\dot{\mathrm{m}}_{\mathrm{w} 2}=4.54 \mathrm{~g} / \mathrm{s}(0.010 \mathrm{lb} / \mathrm{s}) ; \mathrm{h}_{\mathrm{z}}=4.54 \mathrm{~g} / \mathrm{s}(0.010 \mathrm{lb} / \mathrm{s}) ; 0 / \mathrm{F}=1.00$

Figure 6: Lowest quality operating conditions for water and water-gel for the triplet injector. 


\section{ORIGINAL PAGE \\ BLACK AND WHITE PHOTOGRAPH}

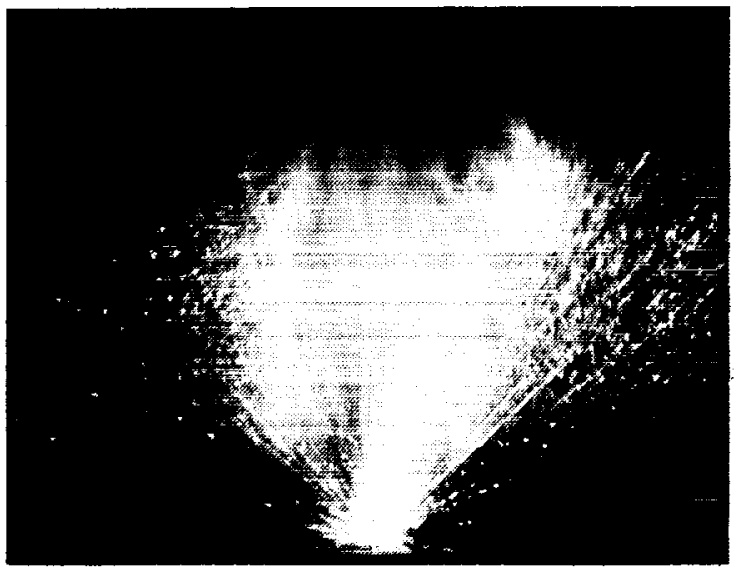

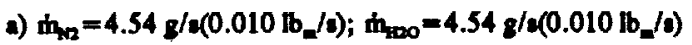

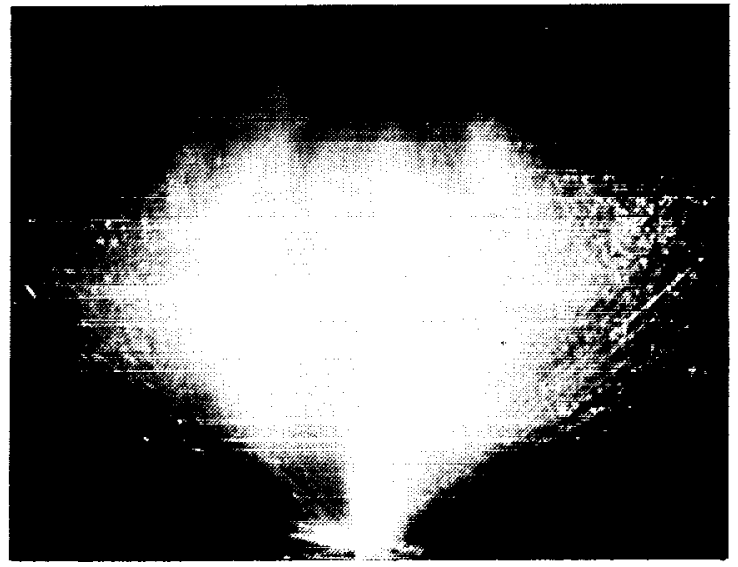

c) $\mathrm{h}_{\mathrm{m} 2}=6.80 \mathrm{~g} / \mathrm{s}(0.015 \mathrm{lb} / \mathrm{h}) ; \mathrm{h}_{\mathrm{zpD}}=6.80 \mathrm{~g} / \mathrm{g}(0.015 \mathrm{lb} \mathrm{z} / \mathrm{h})$

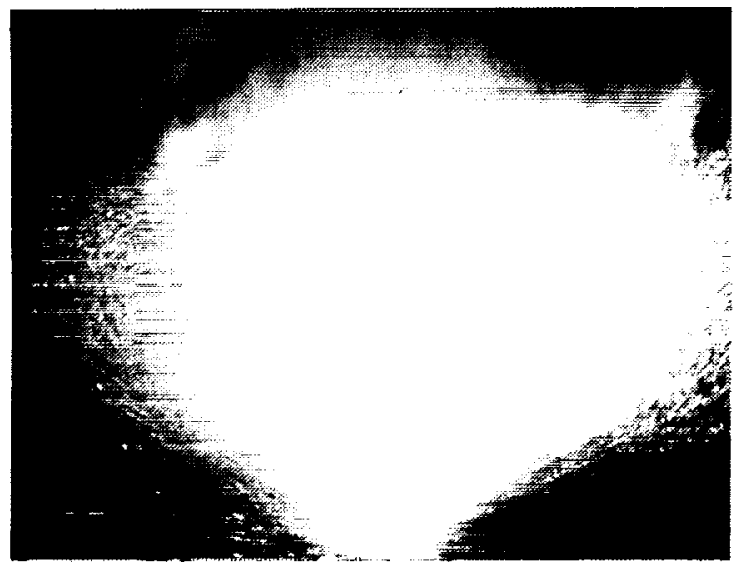

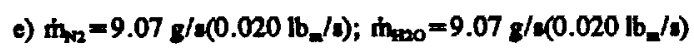

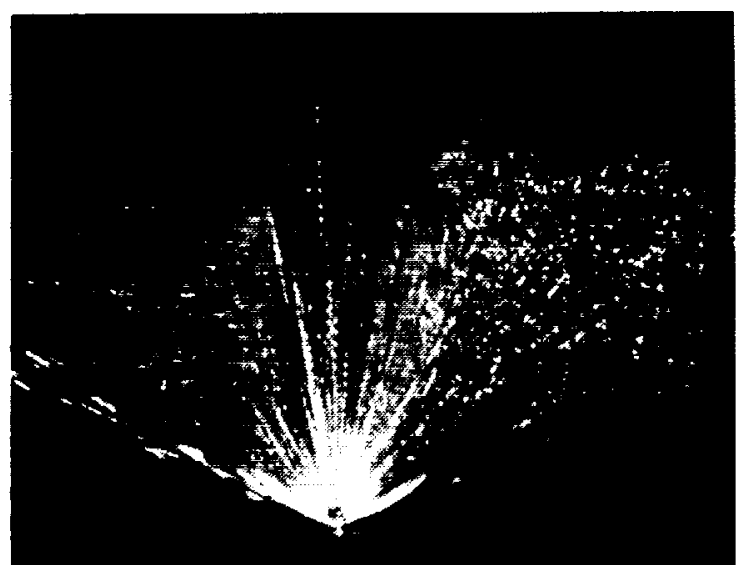

b) $\dot{m}_{w_{2}}=4.54 \mathrm{~g} / \mathrm{s}(0.010 \mathrm{lb} / \mathrm{s}) ; \mathrm{m}_{\mathrm{s}}=4.54 \mathrm{~g} / \mathrm{a}(0.010 \mathrm{lb} / \mathrm{z})$

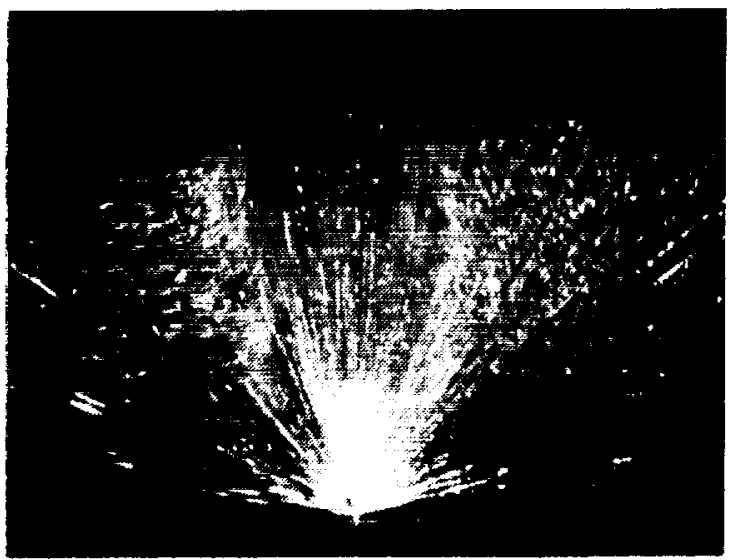

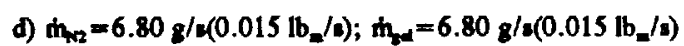

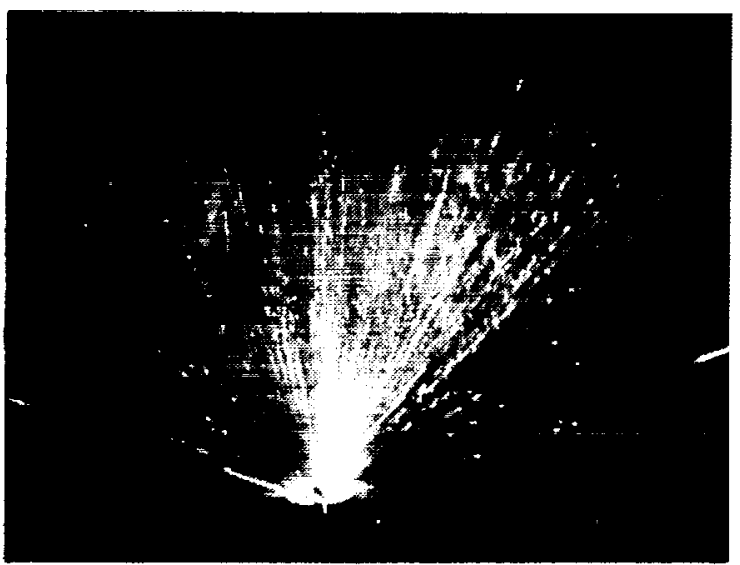

f) $\mathrm{m}_{\mathrm{w}}=9.07 \mathrm{~g} / \mathrm{s}(0.020 \mathrm{lb} / \mathrm{s}) ; \mathrm{h}_{\mathrm{z}}=9.07 \mathrm{~g} / \mathrm{s}(0.020 \mathrm{lb} / \mathrm{g})$

Figure 7: The effect of total mass flow rate on water and water-gel atomization for the triplet injector for $\mathrm{O} / \mathrm{F}=1.0$. 


\section{ORIGINAL PAGE \\ BLACK AND WHITE PHOTOGRAPH}

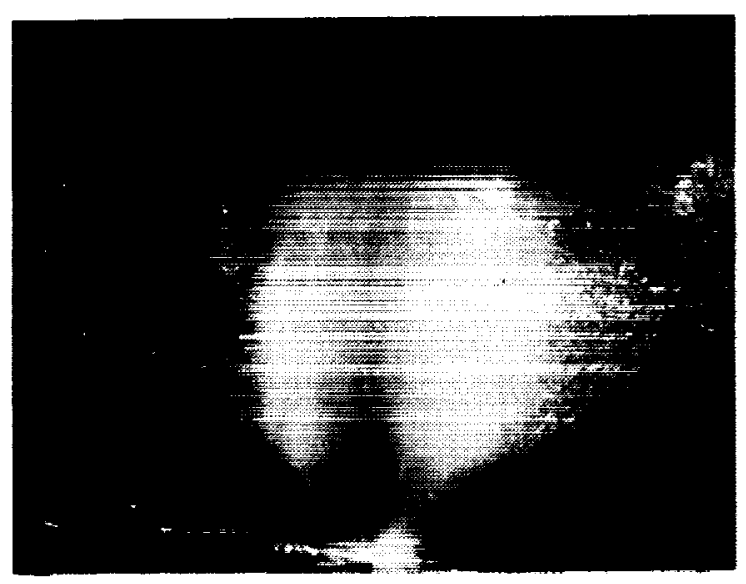

a) $\mathrm{H}_{\mathrm{ta0}}=4.54 \mathrm{~g} / \mathrm{(t}(0.010 \mathrm{Jb} / \mathrm{l})$

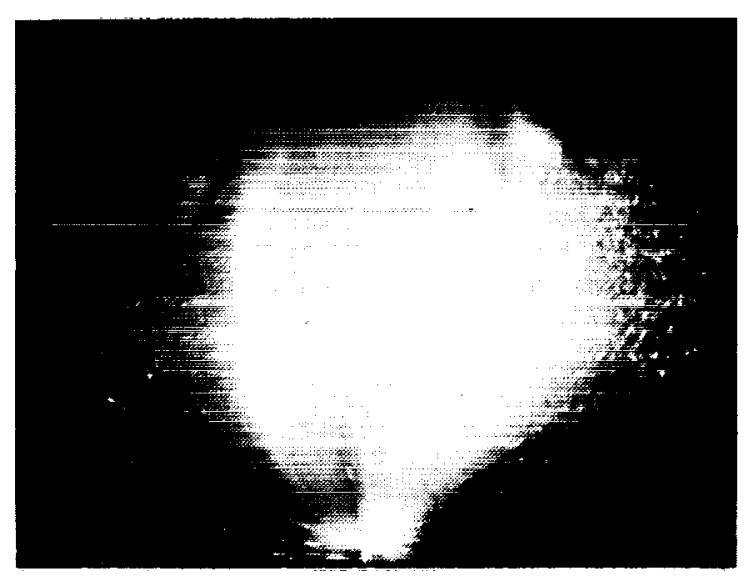

c) $\mathrm{t}_{\mathrm{rno}}=7.57 \mathrm{~g} / \mathrm{g}(0.017 \mathrm{~b} / \mathrm{s})$

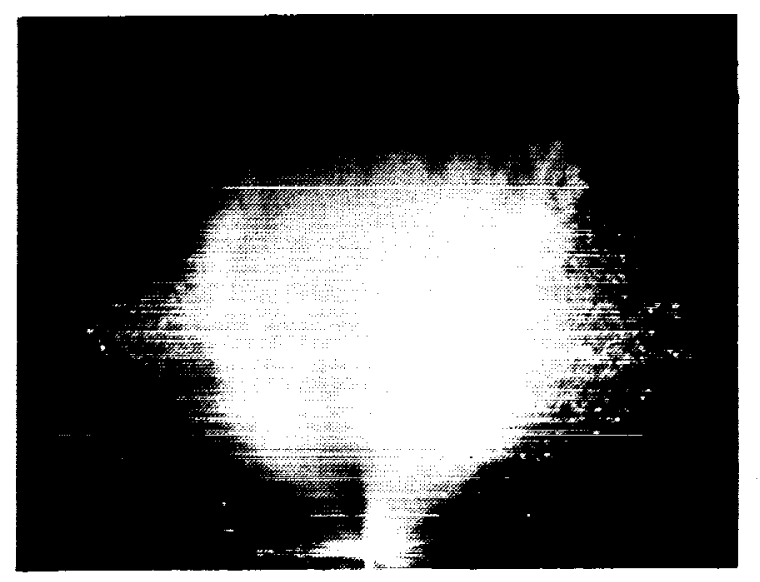

b) $h_{\text {tro }}=6.80 g /(0.015 \mathrm{tb} / \mathrm{s})$

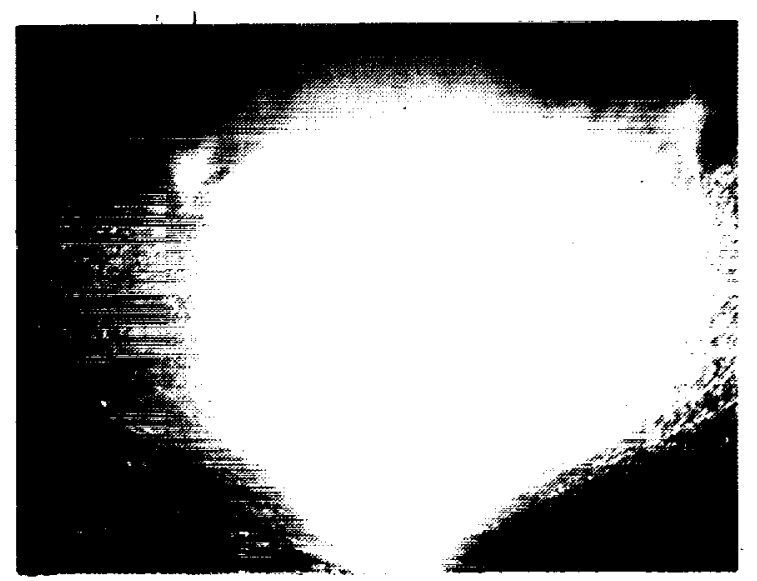

d) $\mathrm{h}_{\mathrm{tr} 0}=9.07 \mathrm{~g} / \mathrm{a}(0.020 \mathrm{~b} / \mathrm{m} / \mathrm{s}$

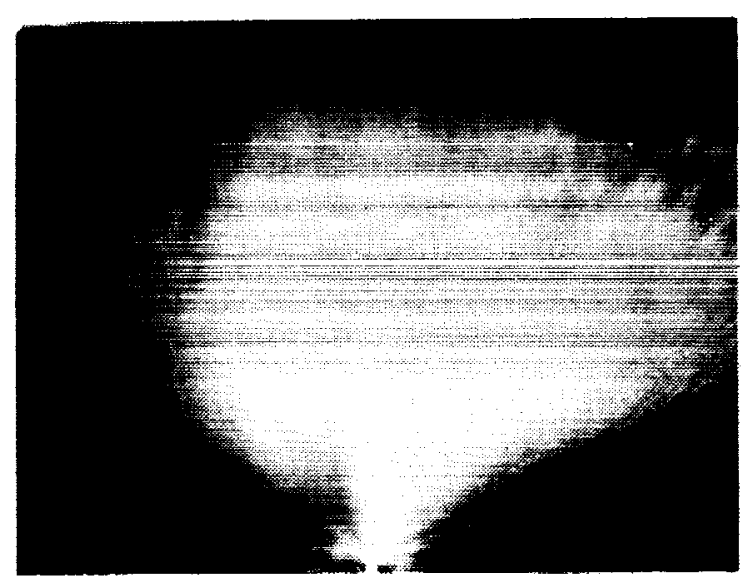

e) $\mathrm{t}_{4+20}=11.34 \mathrm{~g} / \mathrm{g}(0.025 \mathrm{~B} / \mathrm{g})$

Figure 8: The effect of water mass flow rate on atomization for the triplet injector for $\mathrm{m}_{\mathrm{N} 2}=9.07 \mathrm{~g} / \mathrm{s}(0.020 \mathrm{lb} / \mathrm{z})$. 


\section{ORIGINAL PAGE \\ 3:ACK AND WHITE PHOTOGRAPH}

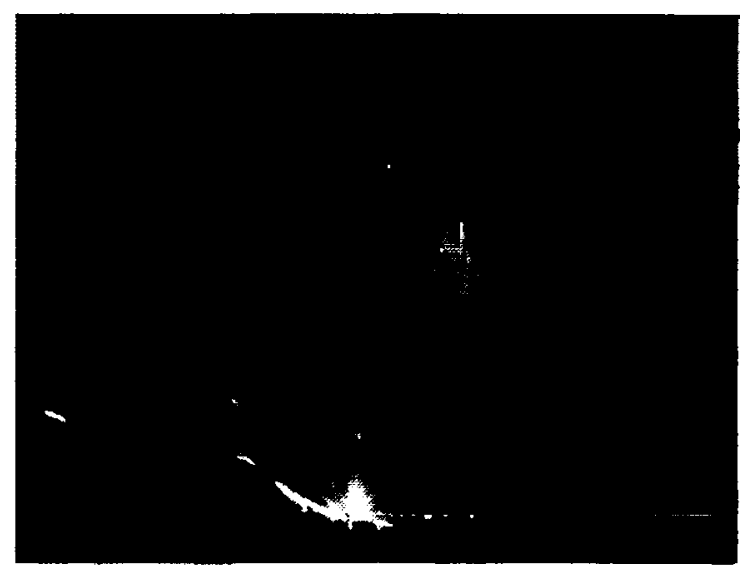

a) $H_{\mathrm{g}}=4.54 \mathrm{~g} / 2(0.010 \mathrm{lb} / \mathrm{s})$

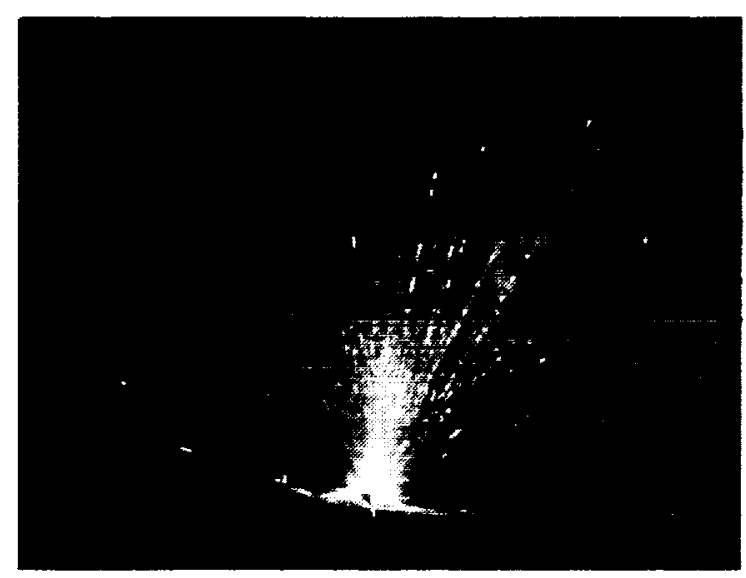

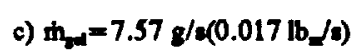

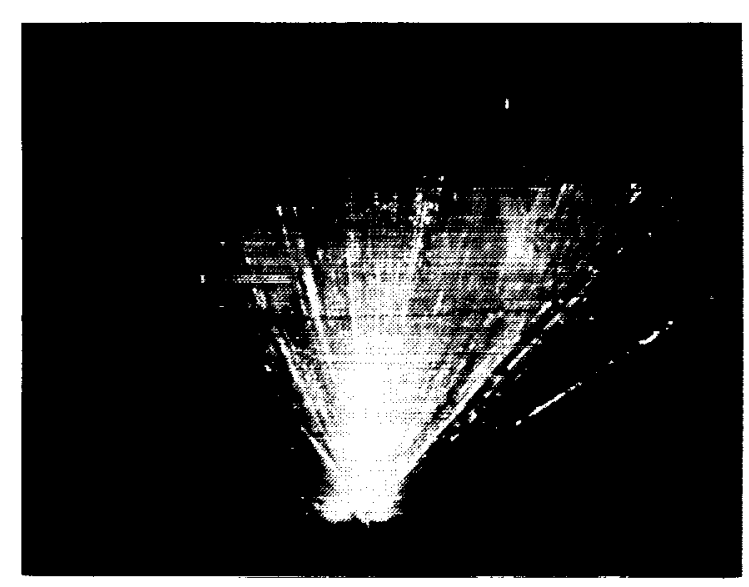

e) $\mathrm{m}_{\mathrm{met}}=11.34 \mathrm{~g} / \mathrm{s}(0.025 \mathrm{bb} / \mathrm{s})$

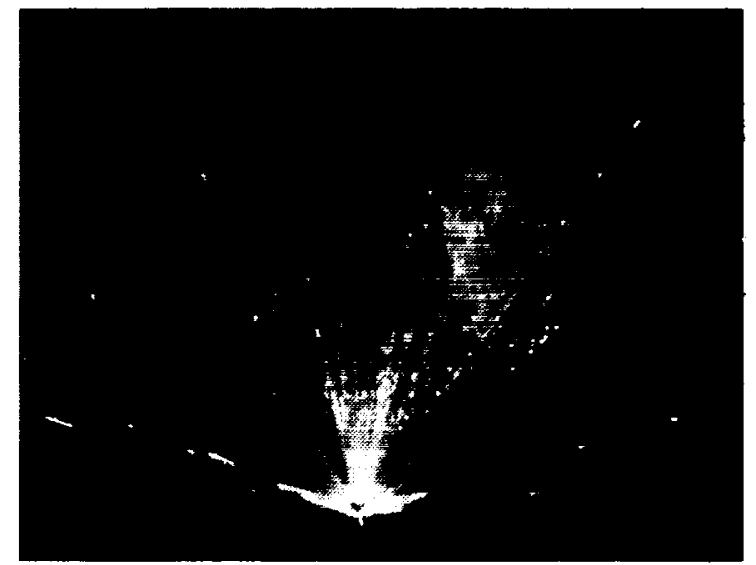

b) $h_{2, d}=6.80 \mathrm{~g} / 2(0.015 \mathrm{th} / \mathrm{s})$

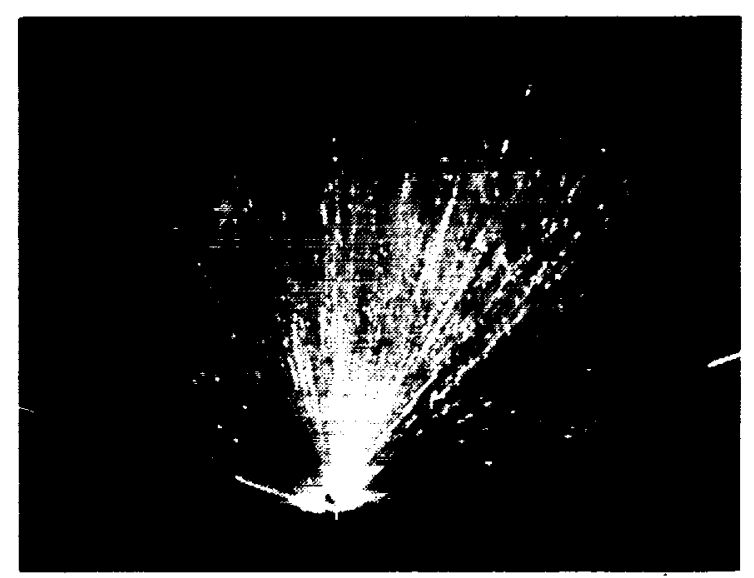

d) $\mathrm{m} / \mathrm{d}=9.07 \mathrm{~g} / \mathrm{s}(0.020 \mathrm{lb} / \mathrm{d})$

Figure 9: The effect of water-gel mass flow rate on atomization for the triplet injector for $\mathrm{m}_{\mathrm{N} 2}=9.07 \mathrm{~g} / \mathrm{s}(0.020 \mathrm{lb} / \mathrm{s})$. 
BLACK AND WHITE PHOTOGRAPH

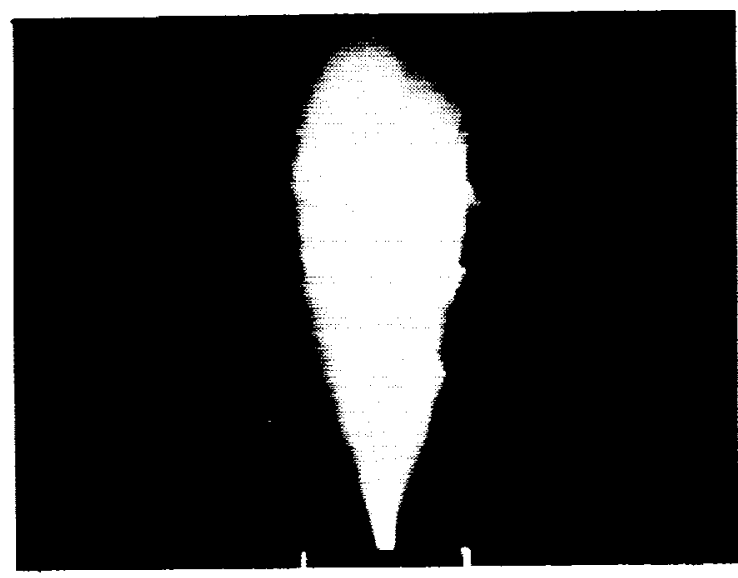

a) $\mathrm{th}_{\mathrm{w2}}=4.54 \mathrm{~g} / \mathrm{s}(0.010 \mathrm{lb} / \mathrm{s}) ; \mathrm{m}_{\mathrm{maO}}=4.54 \mathrm{~g} / \mathrm{g}(0.010 \mathrm{lb} / \mathrm{b})$

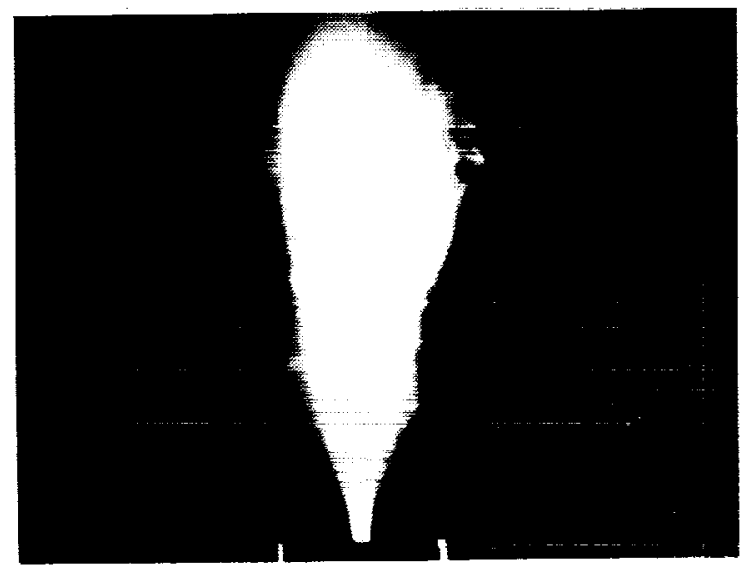

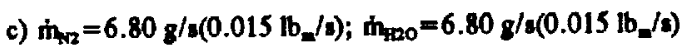

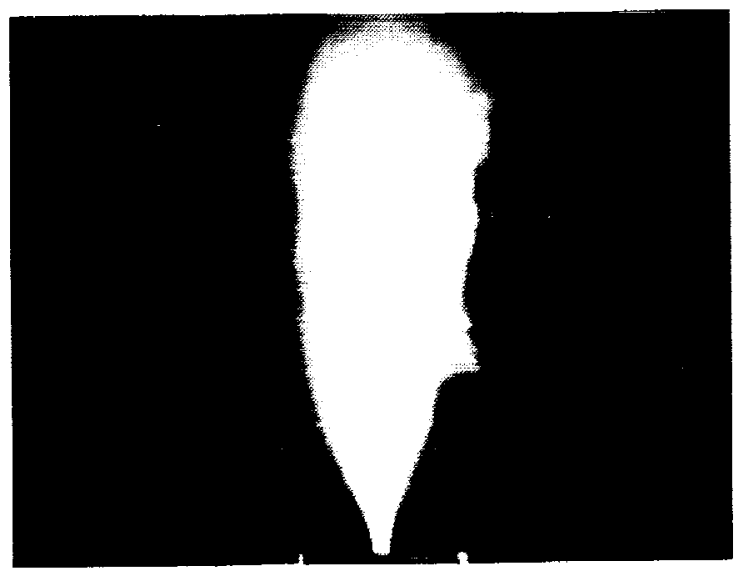

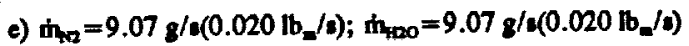

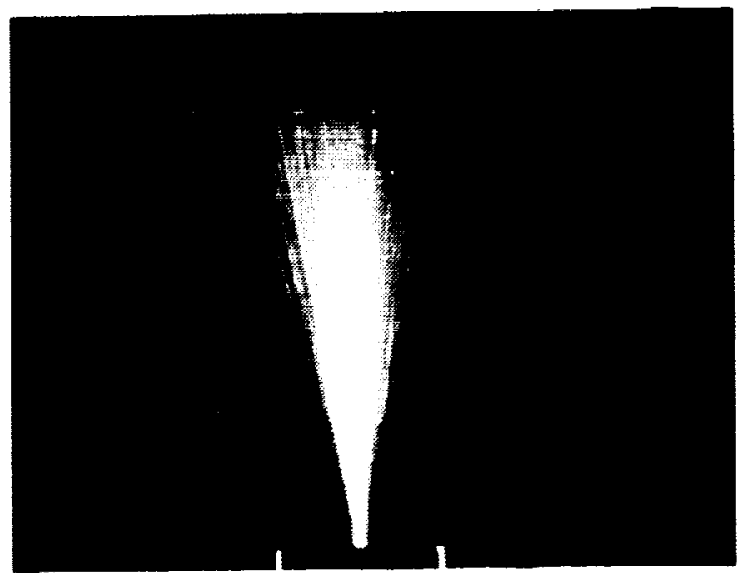

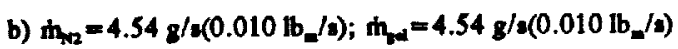

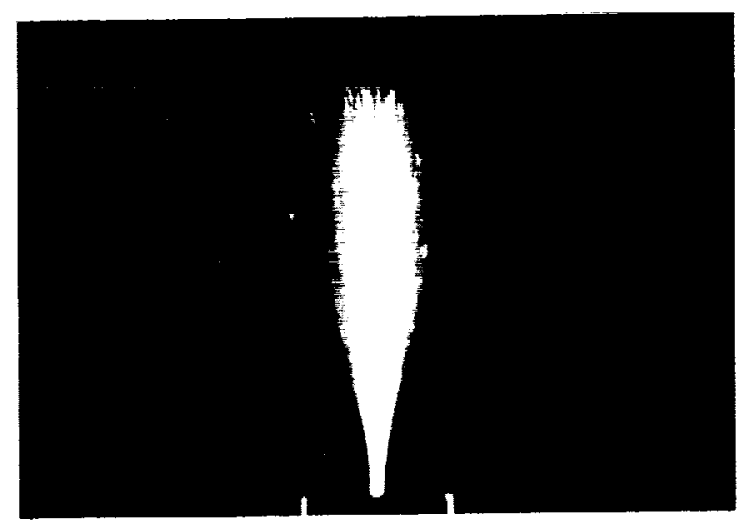

d) $\mathrm{t}_{\mathrm{wz}}=6.80 \mathrm{~g} / \mathrm{g}(0.015 \mathrm{lb} / \mathrm{s}) ; \mathrm{m}_{\mathrm{sd}}=6.80 \mathrm{~g} / \mathrm{s}(0.015 \mathrm{lb} / \mathrm{s})$

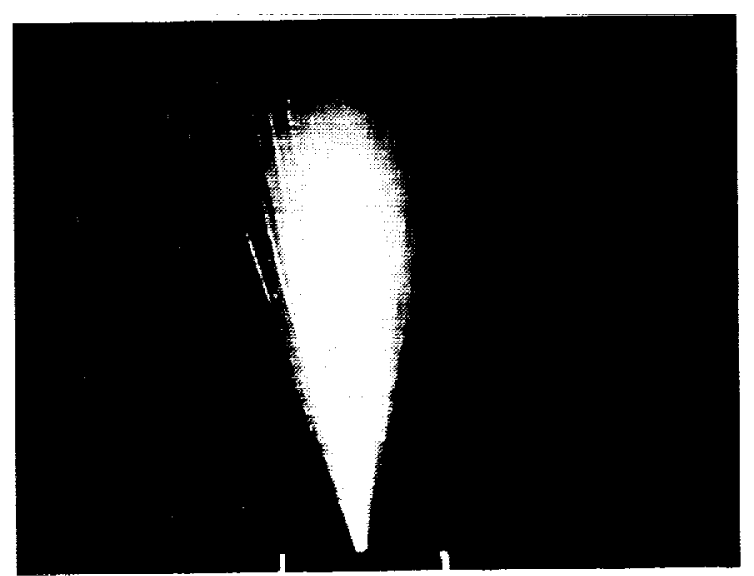

f) $\mathrm{m}_{\mathrm{wg}}=9.07 \mathrm{~g} / \mathrm{m}(0.020 \mathrm{lb} / \mathrm{s}) ; \mathrm{m}_{\mathrm{wd}}=9.07 \mathrm{~g} / \mathrm{s}(0.020 \mathrm{lb} / \mathrm{s})$

Figure 10: Images of the coaxial injector at varying total mass flow rate for $O / F=1.0$. 
constant liquid mass flow rate. Additional information is required from a larger number of test conditions to quantify the effect that liquid and gas mass flow rates and gas/liquid momentum ratio have on gelled propellant atomization.

\section{Coaxial Injector Results}

While the triplet element produced a spray fan that varied dramatically for different operating conditions, the coaxial element produced a uniform cone that showed little change for the entire range of operating conditions for each liquid. Due to this uniformity, qualitative analysis of the coaxial injectors is difficult, and droplet size data are required to determine the optimum conditions and trends in the data for the coaxial element test conditions. Despite the lack of information on trends in the spray data, the differences between water and water-gel are clear in the current images. Figure 10 shows the three conditions for both water and water-gel with mixture ratios equal to 1.0 and different total mass flow rates. This figure emphasizes the fact that the water spray is atomized into finer drop size distributions than the water-gels, for the same reasons as outlined in the triplet injector results.

\section{CONCLUSION}

An experimental program was conducted at the NASA Lewis Research Center to compare the atomization characteristics of gelled and non-gelled propellant simulants. Water was used to isolate the rheological effects of the water-gel and to simulate a non-gelled RP-1 propellant, and a water-gel was formulated which simulated the shear-thinning properties of an aluminum/RP-1 metallized gelled propellant. Photographic images were obtained which identified the qualitative differences between water and water-gel sprays. By maintaining relatively constant liquid surface tension, density, and flow velocity conditions between non-gelled and gelled fluids, rheological effects on liquid spray characteristics were evaluated. Viscous forces dominated over inertial forces with the gelled water as evidenced by the delay in the onset of turbulence. The photographs clearly illustrated that increased fluid viscosity led to decreased atomization quality, and that atomization improved as liquid flow rate and overall flow rate increased for both water and watergel.

Quantification of spray properties is required to identify the magnitude of the fluid rheological influence. Understanding of this rheological effect will allow for the further evaluation of surface tension effects and enable operating conditions and hardware designs to be defined which produce uniform sprays of small droplets. To quantitatively assess the atomization characteristics of gelled propellant simulants, images of sufficient resolution to provide droplet size distribution measurements are required. This information can then be used to improve the design of non-Newtonian liquid injectors and thereby improve the combustion efficiency of metallized propellant fueled rocket engines.

\section{ACKNOWLEDGEMENTS}

This work was sponsored by the NASA Lewis Research Center under contract NAS3-25266 with Mr. Bryan A. Palaszewski as monitor. The authors would like to acknowledge Ms. Aimee R. Andrews, Mr. John B. Blankenship, Mr. J. David Clinton, Mr. Richard A. Gardin, Mr. Jay C. Owens, and everyone at the Rocket Lab who helped perform this work.

\section{NOMENCLATURE}

Al

d

K

n

pH

$R^{2}$

$S_{x y}$

$S_{x}$

$S_{\mathrm{y}}$

RP-1

$\mathbf{v}$

DW

WG

$\mathbf{N}$

$\dot{\gamma}$

$\rho$

$\sigma$

$\boldsymbol{\tau}$

Subscripts

$\begin{array}{ll}\text { a } & \text { Apparent } \\ \mathbf{e} & \text { Effective } \\ \mathbf{w} & \text { Wall } \\ \mathbf{y} & \text { Yield }\end{array}$

Yield
Aluminum

Flow Passage Diameter $(\mathrm{cm})$

Power Law Coefficient (Pa.sn)

Power Law Exponent

Acid-Base Scale

Correlation Coefficient, $R^{2}=S_{x y} / S_{x} S_{y}$

Sample Covariance

Standard Deviation in $\mathrm{x}$

Standard Deviation in $y$

Rocket Propellant-1, (Kerosene)

Flow Velocity $(\mathrm{cm} / \mathrm{s})$

Domestic Water

Water-Gel

Nitrogen

Shear Rate $\left(\mathrm{s}^{-1}\right)$

Density $(\mathrm{g} / \mathrm{cc})$

Equilibrium Surface Tension (N/m)

Shear Stress $(\mathrm{Pa})$ 


\section{REFERENCES}

1. Palaszewski, Bryan A.; "Advanced Launch Vehicle Upper Stages Using Liquid Propulsion and Metallized Propellants"; NASA TM 103622, October 1990.

2. Palaszewski, Bryan A.; "Lunar Missions Using Chemical Propulsion: System Design Issues"; NASA TP-3065, January 1991.

3. Palaszewski, Bryan A.; "Metallized Propellants for the Human Exploration of Mars"; NASA TP 3062, November 1990.

4. Zurawski, Robert L.; "Current Evaluation of the Tripropellant Concept"; NASA TP-2602, June 1986.

5. Zurawski, Robert L. and Green, James M.; "An Evaluation of Metallized Propellants Based on Vehicle Performance"; AIAA-87-1773, June 1987.

6. General Dynamics Space Systems Division; "Liquid Rocket Booster Study Final Report Volume II"; Contract NAS8-37137, March 1989.

7. Giffoni, S.F.; "Combustion Evaluation of Thixotropic Gel Slurry Fuels"; in the proceedings of the Metallized Gelled Propellants Conference, published by CPIA, June 1963.
8. Linne, Diane L.; "An Experimental Evaluation of the Combustion Efficiency of an Aluminized Hydrocarbon (JP10) in a Sub-Scale Rocket Engine"; Master's Thesis, Case Westem Reserve University, May 1990.

9. Zaller, M., "LOX/Hydrogen Coaxial Injector Atomization Test Program", NASA CR187037, in the Proceedings of the 27th JANNAF Combustion Meeting, Chemical Propulsion Information Agency, 1990.

10. The B.F. Goodrich Company, "Carbopol Water Soluble Resins, " Technical Paper GC-67, B.F. Goodrich Company, Specialty Polymers \& Chemicals Division, 1987.

11. CRC Press, Handbook of Chemistry and Physics, 62nd Edition, 1981-1982.

12. Rapp, Douglas C., "Rheology of Aluminum/RP-1 Metallized Propellants Employing Gelling and Surface Active Agents," Case Western Reserve University, Masters Thesis, May 1989.

13. Rapp, Douglas C., and Zurawski, Robert L., "Characterization of Aluminum/RP-1 Gel Propellant Properties," AIAA Paper 88-2821, July 1988. (NASA TM-100951.) 


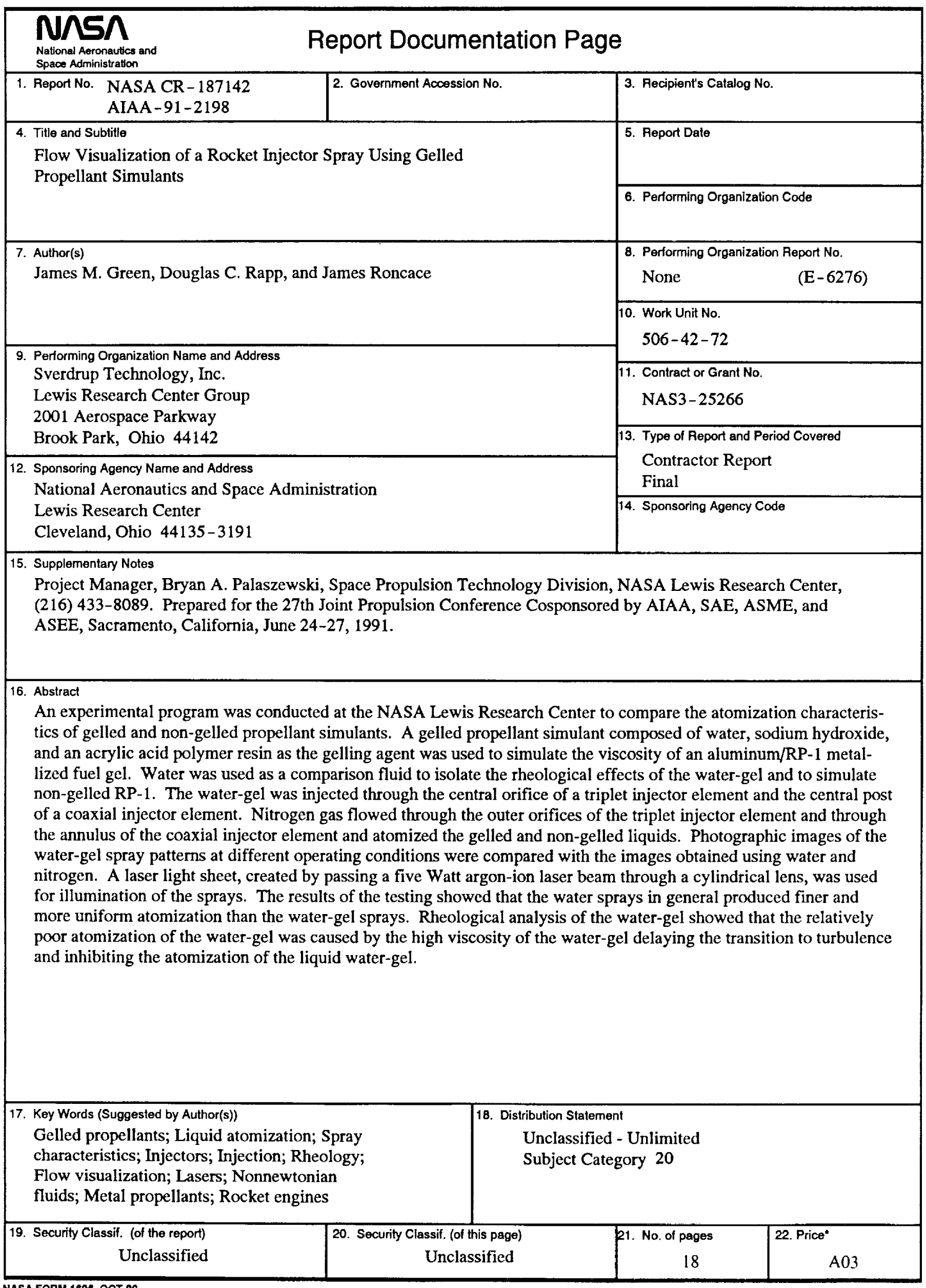


